\title{
IFN $\gamma$ Enhances CD64-Potentiated Phagocytosis of Treponema pallidum Opsonized with Human Syphilitic Serum by Human Macrophages
}

\section{OPEN ACCESS}

Edited by:

Abhay Satoskar,

The Ohio State University

Columbus, United States

Reviewed by: Monica E. Embers,

Tulane University, United States

Sanjay Ram,

University of Massachusetts

Medical Center

United States

Carlos Robello,

Institut Pasteur de Montevideo,

Uruguay

*Correspondence:

Juan C. Salazar

jsalaza@connecticutchildrens.org

tPresent address:

Jorge L. Cervantes,

Paul L. Foster School of Medicine,

Texas Tech University Health

Sciences Center, El Paso, TX,

United States

Specialty section:

This article was submitted to

Microbial Immunology,

a section of the journal

Frontiers in Immunology

Received: 18 April 2017 Accepted: 15 September 2017 Published: 05 October 2017

Citation:

Hawley KL, Cruz AR, Benjamin SJ, La Vake CJ, Cervantes JL, LeDoyt M, Ramirez LG, Mandich D, Fiel-Gan M,

Caimano MJ, Radolf JD and

Salazar JC (2017) IFNy Enhances CD64-Potentiated Phagocytosis of

Treponema pallidum Opsonized with Human Syphilitic Serum

by Human Macrophages.

Front. Immunol. 8:1227.

doi: 10.3389/fimmu.2017.01227
Kelly L. Hawley ${ }^{1,2}$, Adriana R. Cruz ${ }^{3}$, Sarah J. Benjamin ${ }^{1,2,4}$, Carson J. La Vake ${ }^{1}$, Jorge L. Cervantes ${ }^{1,2 \dagger}$, Morgan LeDoyt ${ }^{5}$, Lady G. Ramirez ${ }^{3}$, Daniza Mandich ${ }^{6}$, Mary Fiel-Gan ${ }^{6}$, Melissa J. Caimano ${ }^{5}$, Justin D. Radolf $f^{1,2,3,4,5,7}$ and Juan C. Salazar ${ }^{1,2,3,4 *}$

${ }^{1}$ Department of Pediatrics, UConn Health, Farmington, CT, United States, ${ }^{2}$ Division of Infectious Diseases, Connecticut Children's Medical Center, Hartford, CT, United States, ${ }^{3}$ Centro Internacional de Entrenamiento e Investigaciones Médicas (CIDEIM), Cali, Colombia, ${ }^{4}$ Department of Immunology, UConn Health, Farmington, CT, United States, ${ }^{5}$ Department of Medicine, UConn Health, Farmington, CT, United States, ${ }^{6}$ Department of Pathology, Hartford Hospital, Hartford, CT, United States, ${ }^{7}$ Department of Genetics and Developmental Biology, UConn Health, Farmington, CT, United States

Syphilis is a multi-stage, sexually transmitted disease caused by the spirochete Treponema pallidum (Tp). Considered broadly, syphilis can be conceptualized as a dualistic process in which spirochete-driven inflammation, the cause of clinical manifestations, coexists to varying extents with bacterial persistence. Inflammation is elicited in the tissues, along with the persistence of spirochetes to keep driving a robust immune response while evading host defenses; this duality is best exemplified during the florid, disseminated stage called secondary syphilis (SS). SS lesions typically contain copious amounts of spirochetes along with a mixed cellular infiltrate consisting of $\mathrm{CD} 4^{+} \mathrm{T}$ cells, $\mathrm{CD} 8^{+} \mathrm{T}$ cells, NK cells, plasma cells, and macrophages. In the rabbit model, Tp are cleared by macrophages via antibodymediated opsonophagocytosis. Previously, we demonstrated that human syphilitic serum (HSS) promotes efficient uptake of Tp by human monocytes and that opsonophagocytosis of Tp markedly enhances cytokine production. Herein, we used monocyte-derived macrophages to study Tp-macrophage interactions ex vivo. In the absence of HSS, monocytederived macrophages internalized low numbers of $T p$ and secreted little cytokine (e.g., TNF). By contrast, these same macrophages internalized large numbers of unopsonized Borrelia burgdorferi and secreted robust levels of cytokines. Maturation of macrophages with M-CSF and IFN $\gamma$ resulted in a macrophage phenotype with increased expression of HLA-DR, CD14, inducible nitric oxide synthase, TLR2, TLR8, and the Fcy receptors (FcyR) CD64 and CD16, even in the absence of LPS. Importantly, IFN $\gamma$-polarized macrophages resulted in a statistically significant increase in opsonophagocytosis of Tp accompanied by enhanced production of cytokines, macrophage activation markers (CD40, CD80), TLRs (TLR2, TLR7, TLR8), chemokines (CCL19, CXCL10, CXCL11), and TH1-promoting cytokines (IL-12, IL-15). Finally, the blockade of FcyRs, primarily CD64, significantly diminished spirochetal uptake and proinflammatory cytokine secretion by IFN $\gamma$-stimulated macrophages. Our ex vivo studies demonstrate the importance of CD64-potentiated uptake of opsonized Tp and suggest that IFN $\gamma$-activated macrophages have an important role in the context of early syphilis. Our study results also provide an ex vivo surrogate system for use in future syphilis vaccine studies.

Keywords: Treponema pallidum, human, macrophage, Fc $\gamma$ receptor, phagocytosis, phagosomal signaling, vaccine model 


\section{INTRODUCTION}

Venereal syphilis is a multistage, sexually transmitted infection caused by the spirochetal bacterium, Treponema pallidum (Tp) $(1,2)$. Syphilis continues to be a major public health threat, affecting nearly 6 million people globally (3). In the United States, the rate of primary and secondary syphilis (SS) has more than tripled from 2.1 cases in 2000 to 6.3 cases per 100,000 in $2014(4,5)$. Syphilitic infection commences clinically with the appearance of an ulcerative lesion, known as a chancre, at the site of inoculation (2). However, even before the appearance of the chancre, treponemes begin to disseminate hematogenously, eventually giving rise to SS, a systemic inflammatory illness associated with diverse clinical manifestations, most commonly involving skin and mucous membranes (2). After weeks to months, the robust cellular and humoral responses elicited during SS gain control of the pathogen, driving down spirochetal burdens and ushering in the asymptomatic stage called latency (2). Approximately one-third of untreated patients will develop one of the recrudescent syndromes collectively known as tertiary syphilis (2). Considered broadly, syphilis can be conceptualized as a dualistic process in which spirochete-driven inflammation, the cause of clinical manifestations, coexists to varying extents with bacterial persistence.

Syphilitic lesions in all stages of disease contain a rich cellular infiltrate, composed primarily of lymphocytes, plasma cells and macrophages, accompanied by vasculopathic changes of varying severity $(6,7)$ capable of giving rise to a wide variety of histological patterns, including granulomata (8). Immunocytochemical analysis has revealed that the relative proportions of $\mathrm{T}$ cell subsets shifts from predominantly $\mathrm{CD} 4^{+} \mathrm{T}$ cells in genital ulcers to a predominance of $\mathrm{CD} 8^{+} \mathrm{T}$ cells in SS lesions $(7,9)$. Innate lymphocytes, more specifically NK cells, also have been identified in biopsies of skin rashes from SS patients (10). Transcriptional and immunofluorescent analyses have revealed that both primary and SS lesions contain classic $\mathrm{T}_{\mathrm{H}} 1$ cytokines and that multiple lymphocytic populations $\left(\mathrm{CD} 4^{+}, \mathrm{CD}^{+}\right.$, and NK cells) can be sources of IFN $\gamma$, the hallmark of a $\mathrm{T}_{\mathrm{H}} 1$ response (10-14). The presence in human lesions of IFN $\gamma$ and activated macrophages $(9,14)$ is consistent with a large body of literature from the experimental rabbit model suggesting that macrophages activated by IFN $\gamma(15-18)$ are critical for spirochete clearance. Seminal ex vivo studies by Lukehart et al. (19-22) have demonstrated that opsonic antibodies present in immune rabbit serum markedly enhance phagocytosis and killing of $T p$ by rabbit peritoneal macrophages. Like their rabbit counterparts, human monocytes and macrophages also require syphilitic serum for efficient spirochetal uptake $(10,23)$. In addition to clearance, opsonophagocytosis of $T p$ also promotes a robust proinflammatory cytokine response which can be attributed to the release of spirochetal pattern-associated molecular patterns (PAMPs), most notably lipoproteins, from organisms degraded in phagosomes (10).

Despite the acknowledged central role of the macrophage in the immunobiology of syphilis, only recently have investigators begun to examine the interactions between $T p$ and human macrophages. We, like others, observed $T p$ infiltrating the epidermis by immunohistologic analysis of secondary syphilitic skin lesions
$(24,25)$. Additionally, $\mathrm{CD} 68^{+}$histiocytes were poised throughout the dermis, at the dermal-epidermal juncture and, in some cases, a few histiocytes were observed in the epidermis. $\mathrm{CD} 138^{+}$plasma cells, a potential source of local opsonic antibodies, made up a portion of the cell-mediated inflammatory response (26). As in the recent communication by Marra et al. (23), herein we report that opsonic antibodies significantly enhance internalization of $T p$ by monocyte-derived human macrophages. However, we also note that IFN $\gamma$ markedly enhances the expression of CD64, the primary receptor for opsonic uptake of treponemes, providing for the first time, mechanistic evidence for the linkage of spirochetal clearance with adaptive cellular responses in vivo. IFN $\gamma$ plays a critical role in macrophage mediated responses by not only increasing opsonophagocytosis of $T p$ but also markedly broadening the inflammatory response of the macrophages following internalization of spirochetes, further emphasizing the interdependence of local innate and adaptive responses during syphilitic infection. However, even with IFN $\gamma$ activation, uptake of $T p$ by macrophages was inefficient as determined by the substantial proportion of spirochetes that were not internalized despite a lengthy preincubation in high concentrations of the anti-treponemal antibodies present in human syphilitic sera (HSS). These latter results are in accord with prior studies showing that $T p$ presents a paucity of surface antigenic targets at the host-pathogen interface and that spirochete populations display a high degree of heterogeneity with respect to surface antibody $(\mathrm{Ab})$ binding. Our findings not only illustrate the dualistic nature of syphilis but also demonstrate the utility of an ex vivo model for teasing apart its many components.

\section{MATERIALS AND METHODS}

\section{Ethics Statement}

This study was carried out in accordance with the recommendations of the Institutional Review Boards at UConn Health, Farmington CT and Centro Internacional de Entrenamiento e Investigaciones Médicas (CIDEIM) in Cali, Colombia. All study participants were provided written informed consent. All animal experimentation was conducted following the Guide for the Care and Use of Laboratory Animals (8th Edition) and in accordance with protocols reviewed and approved by the UConn Health Institutional Animal Care and Use Committee under the auspices of Animal Welfare Assurance A347-01.

\section{Immunohistochemical (IHC) Analysis of SS Skin Biopsies}

Four micrometer sections, cut from a 4-mm punch biopsy that were fixed in $10 \%$ buffered formalin and embedded in paraffin, were stained with hematoxylin and eosin (H\&E) or labeled immunohistochemically with antibodies against CD4 (clone EP204, Epitomics, Cambridge, MA), CD8 (clone 4B11, Leica Biosystems Inc., Buffalo Grove, IL), CD56 (clone 56C04 Thermo-Scientific, Waltham, MA), CD68 (clone PG-M1, Dako, Carpinteria, CA) and CD138 (clone B-A38 Cell Marque, Rocklin, CA) using an automated immunohistochemistry staining platform (Bond Max, Leica-Microsystems, Buffalo Grove, IL). IHC detection of 
Tp was performed manually as previously described (10) using a rabbit polyclonal anti-Tp Ab (Biocare, Concord, CA, USA). Skin specimens from healthy volunteers of the same socioeconomic background and conditions were not available for analysis. Tissue known to contain $T p$ were used for the positive control of $T p$ IHCs. Additionally, secondary alone controls were used to assess any non-specific $\mathrm{Ab}$ binding for each $\mathrm{Ab}$ used.

\section{Bacterial Strains}

Treponema pallidum (Nichols strain) was propagated by intratesticular inoculation of adult male New Zealand white rabbits and harvested in CMRL medium (Gibco) supplemented with $10 \%$ fetal bovine serum (FBS) (Atlantic Biologicals, Miami, FL, USA) at peak orchitis (12). Spirochetes were enumerated by dark-field microscopy on a Petroff-Hausser counting chamber (Hausser Scientific, Horsham, PA, USA). Virulent Borrelia burgdorferi $(B b)$ strain 297 encoding green fluorescent protein on a cp32-based shuttle vector (27) was propagated in BSK-H medium containing 6\% rabbit serum (Sigma-Aldrich Chemical Co., St. Louis, MO, USA) and $400 \mu \mathrm{g} / \mathrm{ml}$ of kanamycin (SigmaAldrich Chemical Co.). For macrophage incubation experiments, $B b$ temperature-shifted from 23 to $37^{\circ} \mathrm{C}$ were grown to late-logarithmic phase $\left(\sim 8 \times 10^{7}\right.$ spirochetes $\left./ \mathrm{ml}\right)$, washed twice with RPMI, and resuspended in RPMI to a final density of $\sim 3 \times 10^{8}$ spirochetes $/ \mathrm{ml}$.

\section{Macrophage Maturation and Activation}

Peripheral blood was obtained from healthy donors determined to be seronegative for syphilis by Rapid Plasma Reagin test and/or Lyme disease by enzyme-linked immunosorbent assay (ELISA) performed in the clinical laboratory at John Dempsey Hospital. Peripheral blood mononuclear cells (PBMCs) were isolated using Lymphoprep and SepMate-50 tubes in accordance with the recommendations of the manufacturer (STEMCELL Technologies, Vancouver, BC, Canada). To generate all macrophage phenotypes, $3 \times 10^{7}$ PBMCs were plated in $10 \mathrm{~cm}$ polystyrene Petri dishes (BD Falcon) and incubated for $2 \mathrm{~h}$ at $37^{\circ} \mathrm{C}$ with $5 \% \mathrm{CO}_{2}$. Adherent cells were washed thoroughly with ice-cold PBS to remove non-monocyte populations. Macrophage nomenclature used throughout follows the recommendations of Murray et al. (28). $\mathrm{M} \Phi(-)$ s were generated by incubating the adherent monocytes in RPMI-1640 (RPMI) medium (Gibco, Thermo-Scientific) supplemented with $20 \%$ heat-inactivated $\left(56^{\circ} \mathrm{C}\right.$ for $\left.30 \mathrm{~min}\right)$ normal human serum (NHS) (CORNING, Corning, NY, USA) and 1\% penicillin-streptomycin $(10,000 \mathrm{U} / \mathrm{ml})$ (Gibco) for 10 days. $\mathrm{M} \Phi(\mathrm{C}) \mathrm{s}$ were generated by incubating the adherent monocytes in RPMI, 20\% heat-inactivated NHS, and $50 \mathrm{ng} / \mathrm{ml}$ of M-CSF (Peprotech, Rocky Hill, NJ, USA) (29) for 10 days. To generate $\mathrm{M} \Phi(\mathrm{IFN} \gamma) \mathrm{s}, \mathrm{M} \Phi(\mathrm{C}) \mathrm{s}$ were divided on day 7 and $2.5 \mathrm{ng} / \mathrm{ml}$ of recombinant IFN $\gamma$ (Roche Diagnostics, Mannheim, Germany) (30) was added to one portion for an additional three days of incubation. Media and cytokines were replenished every 3 days for a total of 10 days. Because Tp lacks endotoxin and would not be encountered by macrophages in syphilitic lesions, LPS, which is often used in macrophage differentiation protocols, was omitted from all culture media.

\section{Human Syphilitic Sera}

All Tp opsonization studies were performed using a pool of deidentified sera collected from five HIV-negative primary or SS patients seen at Parkland Memorial Hospital in Dallas, TX, USA (approved for use by the Institutional Review Board of the UConn Health) (31). Strong reactivity of the pool with Tp proteins was confirmed by immunoblot (Trinity Biotech, Carlsbad, CA, USA, Figure S2 in Supplementary Material).

\section{Tp Opsonophagocytosis Assays}

Freshly harvested $T p$, adjusted to a final concentration of $3 \times 10^{8}$ treponemes $/ \mathrm{ml}$, were incubated with either $10 \%$ NHS or $10 \%$ pooled HSS for $2 \mathrm{~h}$ at RT prior to addition to macrophages. Macrophages, differentiated as described above, were plated at $1 \times 10^{5}$ cells in $500 \mu \mathrm{l}$ of RPMI supplemented with $10 \%$ heatinactivated FBS (Hyclone Laboratories, Inc., Logan, UT, USA) in an eight-well chamber microscopy slide (Millipore, Billerica, MA, USA). Tp were added at a multiplicity of infection (MOI) of $30: 1$ for $8 \mathrm{~h}$ at $37^{\circ} \mathrm{C}$ with $5 \% \mathrm{CO}_{2}$. All culture media and reagents were confirmed to be free of LPS contamination $(\leq 10 \mathrm{pg} / \mathrm{ml})$ by Limulus amebocyte lysate assay quantification (Cambrex, MA, USA). Following incubation, supernatants were removed and macrophages were prepared for IFA to evaluate binding and uptake of treponemes. Cells were fixed and permeabilized with $2 \%$ paraformaldehyde and $0.01 \%$ Triton X-100 for 10 min at RT. They then were rinsed with PBS, blocked with PBS containing $10 \%$ normal goat serum (NGS) for $1 \mathrm{~h}$ at RT, and then incubated with rabbit polyclonal anti-Tp (1:100, Abcam, Cambridge, MA, USA) in PBS $1 \%$ NGS for $1 \mathrm{~h}$ at RT. After four successive washes with PBS, the cells were then incubated with goat anti-rabbit immunoglobulin G (IgG)-Texas Red (1:500) in PBS 1\% NGS for $1 \mathrm{~h}$ at RT. After staining for Tp, actin cytoskeletons were stained with Phalloidin-AF488 (1:20) (Life Technologies, Carlsbad, CA, USA) for $20 \mathrm{~min}$ at RT. The cells were then washed thoroughly with PBS six times, rinsed with deionized water to remove salt and allowed to air dry. Finally, Vectashield containing DAPI (Vector Laboratories, Inc., Burlingame, CA, USA) was added and samples were sealed with a coverslip. To assess binding and internalization of $T p$, images of 100-200 macrophages were acquired on an Olympus BX60 epifluorescence microscope equipped with a Retiga 2000R CCD camera (QImaging) or Ziess LSM 780 confocal microscope mounted on an inverted Axio Observer Z1. Similar numbers of macrophages were imaged for each experimental condition per biological replicate. Acquired images were processed with ImageJ (version 1.5.1 g) (NIH, USA) and uptake was quantitated in a blinded fashion. The percentage of macrophages with bound spirochetes was quantified by dividing the number of cells with surface bound spirochetes by the total number of macrophages imaged for each condition. The percentage of spirochete-positive macrophages were calculated by dividing the number of cells containing $\geq 1$ internalized spirochetes by the total number of cells imaged. Phagocytic indices were calculated by dividing the number of degraded, internalized spirochetes by the total number of spirochete-positive macrophages for the same condition. To quantify the percentage of $T p$ remaining after the $8 \mathrm{~h}$ incubation period, $10 \mu \mathrm{l}$ aliquots 
from $T p$-stimulated-macrophage supernatants were enumerated, in triplicate, by dark-field microscopy. Percentage of $T p$ recovered was calculated using a "time zero" spirochetal count.

\section{Bb Phagocytosis Assays}

$\mathrm{M} \Phi(-)$ s, after maturation as described above, were plated at $1 \times 10^{5}$ cells in $500 \mu$ of RPMI supplemented with $10 \%$ FBS in an eight-well chamber microscopy slide and incubated at $37^{\circ} \mathrm{C}$ with $5 \% \mathrm{CO}_{2}$ overnight to allow for attachment. Prior to incubation, medium was removed and replaced with fresh RPMI supplemented with 10\% FBS. $B b$ were added at an MOI of 30:1 and incubated for $8 \mathrm{~h}$. Following incubation, cells were fixed and permeablized and cytoskeletons were stained with Phalloidin-AF594 as described above. Binding and internalization of spirochetes was performed as described above.

\section{Cytokine Analysis}

TNF, IL-6, IL-1 $\beta$, IL-10, IL-12, and IL-8 were measured in supernatants using a Human Inflammatory Cytokine Bead Array per the manufacturer's (BD Biosciences, San Jose, CA, USA) protocol. Data were collected on a MACSQaunt Analyzer (Miltenyi Biotec, Germany) and analyzed with FCAP Array ${ }^{\mathrm{TM}}$ Software version 3.0 (BD Biosciences).

\section{Flow Cytometry}

$\mathrm{M} \Phi(\mathrm{C}) \mathrm{s}$ and $\mathrm{M} \Phi(\mathrm{IFN} \gamma) \mathrm{s}$ were harvested from $10-\mathrm{cm}$ polystyrene Petri dishes by replacing growth medium with PBS containing 1\% FBS and gently lifting the cells with a scraper. The macrophages were washed once with PBS in $50 \mathrm{ml}$ conical tubes by spinning at $300 \mathrm{~g}$ for $10 \mathrm{~min}$; the cells were decanted, resuspended in PBS 1\% FBS, and dispensed into FACS tubes in preparation for staining. Cells were incubated for $10 \mathrm{~min}$ at $4^{\circ} \mathrm{C}$ with $10 \mu \mathrm{g} / \mathrm{ml}$ of purified human IgG (Sigma, St. Louis, MO, USA) for Fc $\gamma$ receptor (FcR) blocking, followed by a $20 \mathrm{~min}$ incubation with fluorochrome-conjugated antibodies. Antibodies obtained from Biolegend (CD32-APC, CD64-PECy7, CD163-PerCP/Cy5.5, CD206-APC, anti-rabbit IgG-BV421), eBioscience (CD14-APC, CD16-PE, TLR2-FITC, TLR4-APC), Novus Biologicals (TLR7-PE, TLR8-AF647), BD Biosciences (HLA-DR-PE), Invitrogen (CD68-FITC), and Abcam [rabbit anti-human inducible nitric oxide synthase (iNOS)] were used at dilutions recommended by the manufacturers. For intracellular staining, the cells were surface-stained as described above, permeabilized in $250 \mu \mathrm{l}$ of Cytofix/Cytoperm solution (BD Biosciences) for $20 \mathrm{~min}$ at $4^{\circ} \mathrm{C}$, washed with PermWash buffer (BD Biosciences), stained with fluorochrome-conjugated antibodies (diluted in $50 \mu \mathrm{l}$ of PermWash buffer) for $30 \mathrm{~min}$ at $4^{\circ} \mathrm{C}$, and washed twice with PermWash and resuspended in FACS buffer. A minimum of 10,000 single cells events were acquired using a BD LSR-II flow cytometer and FACSDIVATM software (BD Biosciences). Analysis of immunostaining was performed using FlowJo V10 for Mac (FlowJo LLC, Ashland, OR, USA). Mean fluorescence intensity (MFI) values were determined after subtracting background fluorescence (32).

\section{Targeted Array Analysis}

$1 \times 10^{6} \mathrm{M} \Phi(\mathrm{C}) \mathrm{s}$ and $\mathrm{M} \Phi(\mathrm{IFN} \gamma) \mathrm{s}$ were plated in $1 \mathrm{ml}$ of RPMI containing $10 \%$ FBS in a 12 -well tissue culture plate (Corning) and incubated with unopsonized or opsonized $T p$ for $8 \mathrm{~h}$ at an MOI 30:1. RNAs were extracted using a NucleoSpin RNA purification kit according to the manufacturer's (Macherey-Nagel Inc., Bethlehem, PA, USA) instructions and their concentrations determined using a Nanodrop spectrophotometer (ThermoScientific). cDNA synthesis was performed using the High Capacity cDNA Archive Kit (Applied Biosystems, Waltham, MA, USA) according to the manufacturer's instructions. Transcripts were amplified using TaqMan ${ }^{\circledR}$ Human Immune Array (384-fluidics card) and TaqMan ${ }^{\circledR}$ Human Phagocytosis Array (96-well plate) per manufacturer's instructions (Applied Biosystems). Briefly, the Immune Array was performed in a $2 \mu 1$ reaction volume containing $62.5 \mathrm{pg}$ of cDNA, and $1 \mu 1$ of gene expression master mix. The Phagocytosis Array was processed in a $20 \mu \mathrm{l}$ reaction volume containing $5 \mathrm{ng}$ of cDNA and $10 \mathrm{ml}$ of gene expression master mix. Commercially available primers (Applied Biosystems) were used to amply transcripts for human IRF3 (Hs01547283_m1), IRF5 (Hs00158114_m1), IRF7 (Hs00185375_m1), and IFNB (Hs00277188_s1) as described previously (33). Amplification reactions were performed using a 7900 HT Fast Real Time thermocycler (Applied Biosystems) using the following conditions: $95^{\circ} \mathrm{C}$ for $20 \mathrm{~min}$, and 40 cycles of $95^{\circ} \mathrm{C}$ for $1 \mathrm{~s}$ and $60^{\circ} \mathrm{C}$ for $20 \mathrm{~s}$. Expression levels for all transcripts were normalized to $G A P D H$ and the relative changes in gene expression between experimental groups were calculated using the $2^{-\Delta \Delta \mathrm{Ct}}$ method (34). To identify genes differentially expressed in the presence of IFN $\gamma$ and absence of $T p$, the average fold changes for unstimulated $M \Phi(I F N \gamma) s$ were calculated relative to the unstimulated $M \Phi(C)$ s. To identify genes differentially expressed in the presence of $T p$, relative fold changes were calculated based on the unstimulated $M \Phi(I F N \gamma) s$ condition, with a two-fold change and $p$-value $<0.05$ threshold (Student's $t$-test) (35). Heat maps and graphs of the fold changes of transcript expression were generated using $\mathrm{R}$ statistical software, version 3.2.2 with package "ggplot2," function "heatmap.2." Fold change values displayed in the heat maps represent the average fold change compared to the corresponding unstimulated $\mathrm{M} \Phi(\mathrm{IFN} \gamma)$. No clustering analysis was performed.

\section{Colocalization of CD64 and Tp}

$1 \times 10^{5} \mathrm{M} \Phi(\mathrm{IFN} \gamma)$ s were plated in $500 \mu \mathrm{l}$ of RPMI supplemented with $10 \%$ FBS in an eight-well chamber microscopy slide and incubated for $8 \mathrm{~h}$ with Tp at an MOI of 30:1. Following incubation, the cells, fixed and permeablized as above, were incubated with mouse anti-human CD64 (1:25, clone 10.1, Abcam) and rabbit polyclonal anti-Tp $1 \mathrm{~h}$ at RT, and then washed four times with PBS followed by incubation for $1 \mathrm{~h}$ at RT with goat antimouse IgG-OregonGreen488 (1:200, Invitrogen, Carlsbad, CA, USA) and goat anti-rabbit IgG-Texas Red (1:500, Life Technologies). Secondary Ab alone controls were evaluated for non-specific binding (Figure S6 in Supplementary Material). Images were acquired on a Zeiss LSM 780 confocal microscope mounted on an inverted Axio Observer Z1 and processed with Image J as described above. Colocalization of Tp and CD64 was visualized using the ImageJ plugin "Colocalization"; the coefficient of colocalization was determined using the plugin "JACoP." 


\section{Fc $\gamma R$ Blocking Experiments}

$\mathrm{M} \Phi(\mathrm{IFN} \gamma) \mathrm{s}$ were pre-incubated with $10 \mu \mathrm{g} / \mathrm{ml}$ of mouse antihuman CD64 (clone 10.1, Abcam), mouse anti-human CD32 (clone 6C4, Affymetrix eBiosciences, San Diego, CA, USA), mouse anti-human CD16 (clone 3G8, Biolegend, San Diego, CA, USA), or $10 \mu \mathrm{g} / \mathrm{ml}$ each of all three antibodies for $1 \mathrm{~h}$ prior to adding spirochetes. Opsonophagocytosis assays were performed as described above.

\section{Statistics}

General statistical analysis was conducted using GraphPad Prism 6.0 h (GraphPad Software, San Diego, CA, USA). Phagocytic uptake/index, Tp recovery counts, cytokine concentrations, cytometric MFI ratio, and fold increase or decrease for each gene transcript assayed were compared among the different stimuli. Either a paired or unpaired Student's $t$-test (i.e., Mann-Whitney test or Wilcoxon test) was used for comparison across two groups. For the analysis of three or more conditions, we used a non-parametric statistical test for trend analysis (Friedman's test with a Dunnett's multiple comparisons post-test analysis). For each experiment, the standard error of the mean was calculated and a $p$-value $<0.05$ was considered significant.

\section{RESULTS}

\section{T. pallidum-Macrophage Interactions in SS Skin Lesions}

To set the stage for our ex vivo studies, we assessed the distribution of macrophages, lymphocytes, and plasma cells in spatial relationship to $T p$ within representative skin punch biopsy specimens obtained from three HIV-negative SS patients. In line with prior studies $(6,7,10,36-39)$, IHC analysis of SS skin biopsies revealed a rich dermal-epidermal infiltrate (Figure 1A), which in addition to $\mathrm{CD}^{+}, \mathrm{CD}^{+}$, and $\mathrm{CD} 56^{+}$lymphocytes (Figure S1 in Supplementary Material), had large numbers of $\mathrm{CD}^{+} 8^{+}$macrophages (40) (Figure 1B). Abundant $\mathrm{CD}^{+} 8^{+}$cells were present throughout the dermis, at the dermal-epidermal juncture, and, in some cases, surrounding vascular structures within the dermis (Figure 1B). Treponemal numbers and locations in the inflamed skin, as well as their spatial proximity with dermal macrophages, varied among samples (Figure 1C). In SS143 skin biopsy, a small cluster of $\mathrm{CD} 68^{+}$macrophages was visualized in close proximity to a spirochete surrounding a blood vessel wall. In SS167 sample, substantial numbers of spirochetes were seen within the interstitium of the papillary dermis (Figures 1B,C). In SS133, large groups of spirochetes also were observed traversing the dermal-epidermal junction and within the stratum basale and stratum spinosum of the epidermis (Figure 1C), whereas very few macrophages were found within the epidermis (Figure 1B). Of particular interest, $\mathrm{CD}_{138^{+}}$plasma cells were commonly observed in perivascular locations and throughout the papillary dermis (Figure 1D). In concert with previously published studies $(2,6,7)$, our current results confirm the presence of macrophages in $T p$ infected tissue, and suggest that the cellular environment may be involved in shaping the phenotype of macrophages, in addition to providing a local source of opsonic antibodies needed for spirochetal recognition and clearance in $T p$ infected tissues.

\section{Primary Human Macrophages Phagocytose Tp in the Presence of HSS but Exhibit a Blunted Cytokine Output}

Having confirmed that the macrophage is an important cellular element of the inflammatory response to the syphilis spirochete in vivo, we next performed ex vivo experiments to directly characterize macrophage- $T p$ interactions. We began by maturing adherent human monocytes into macrophages using $20 \%$ heatinactivated NHS without additional exogenous growth factors (e.g., M-CSF). We then assessed the ability of these macrophages $[\mathrm{M} \Phi(-)]$ to bind and phagocytose spirochetes. As a phagocytosis control, we incubated $\mathrm{M} \Phi(-)$ s with $B b$, a spirochetal pathogen that is readily bound and internalized by primary human phagocytes $(41,42)$. As shown in Figure 2A and quantified in Figure $2 \mathbf{B}, B b$ binds to $\mathrm{M} \Phi(-) \mathrm{s}$ and is internalized into phagosomal vacuoles (Figures $\mathbf{2 A}, \mathbf{C}$ ). We then assessed if macrophages were able to similarly bind and internalize $T p$ in the presence or absence of NHS or with HSS. For these experiments, we first confirmed that our pooled HSS reacted with spirochetal antigens by using a Tp IgG Marblot strip test (Figure S2 in Supplementary Material). The pooled HSS was determined to be highly reactive with many of $T p$ 's proteins, likely including some opsonic targets. It is important to note that we previously demonstrated that the same pooled HSS recognizes the Nichols strain variant of L4, an immunodominant extracellular loop in the $\beta$-barrel of BamA and opsonic target (31).

As shown in Figure 2, Tp binds to macrophages with or without NHS. The observed binding does not cause a concomitant increase in bacterial uptake, which suggests that $T p$ attaches to a non-phagocytic receptor yet to be defined on the macrophage's surface. On the other hand, addition of HSS caused a significant increase in spirochetal uptake (Figures 2A,C). In line with the increased uptake of opsonized $T p$, fewer spirochetes were visualized bound to the macrophage surface (Figure 2B). Interestingly, while internalization of $B b$ resulted in copious secretion of TNF, opsonophagocytosis of $T p$ did not (Figure 2D). These findings confirm that HSS promotes opsonophagocytosis of Tp by human macrophages, but also raise the possibility that the milieu in which macrophages encounter spirochetes is an important determinant of macrophage activation and cytokine production following internalization of bacteria.

\section{IFN $\gamma$ Induces a Classically Activated Immunophenotype in Human Macrophages}

The observation that cytokine production in $T p$ stimulated $M \Phi(-) s$ was unexpectedly low prompted us to generate a macrophage phenotype that more closely resembles macrophages present within an IFN $\gamma$ rich syphilitic immune microenvironment in vivo $(10,14)$. To do so, human monocytes were differentiated into macrophages by adding M-CSF alone 


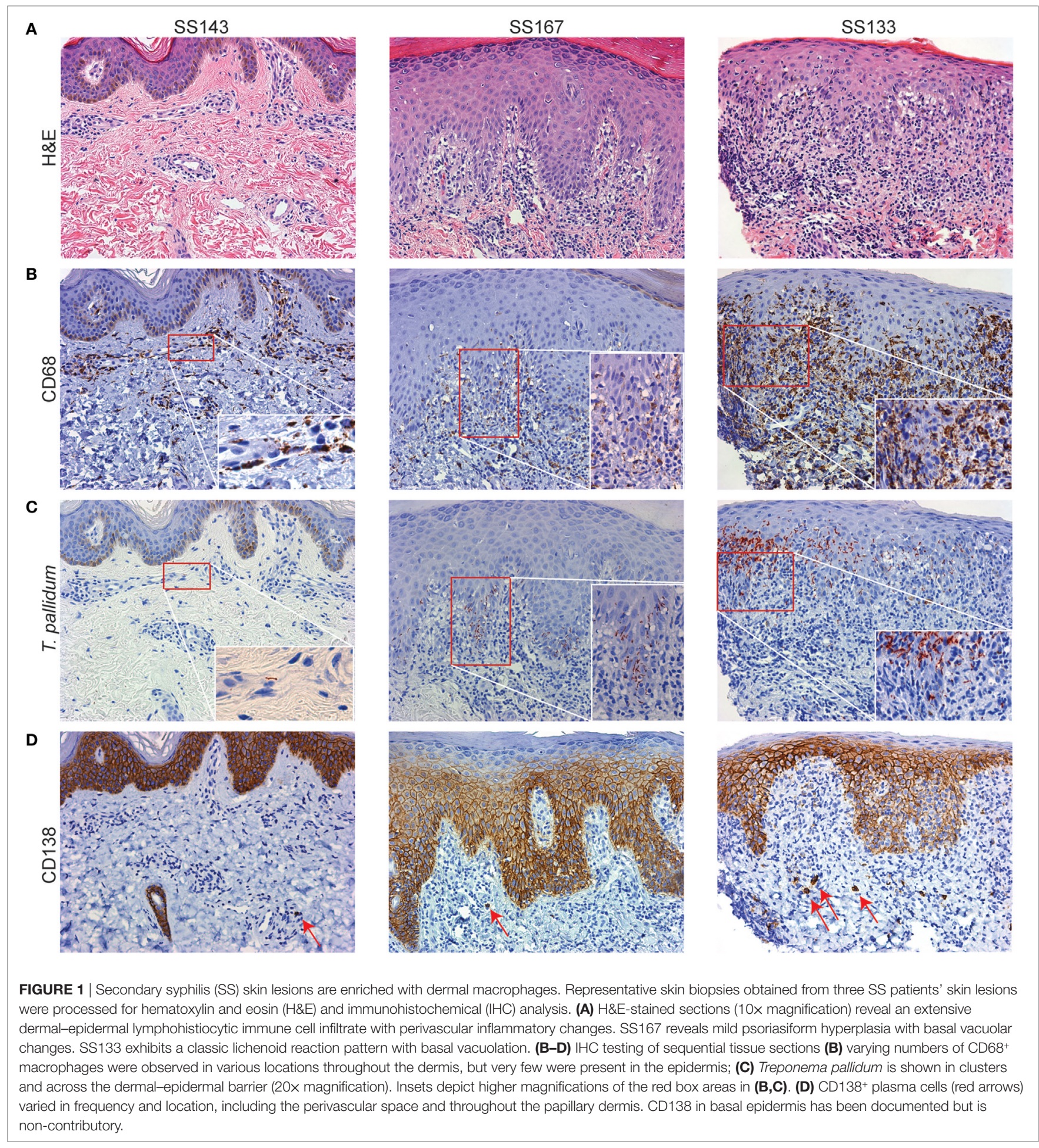

$[\mathrm{M} \Phi(\mathrm{C})]$ or M-CSF with IFN $\gamma[\mathrm{M} \Phi(\mathrm{IFN} \gamma)]$ and then characterized by flow cytometry, gene transcript analysis, and cytokine responsiveness. Given that $T p$ is completely devoid of LPS (43), we omitted this potent endotoxin from our maturation protocols, whereas LPS is often used in macrophage stimulation experiments $(29,44,45)$. To more clearly define the effect of IFN $\gamma$, we first had to measure the expression of several markers associated with either classically and/or alternatively activated macrophages $(29,46,47)$. Expression of CD68, a well characterized macrophage marker, was unaffected by IFN $\gamma$ 


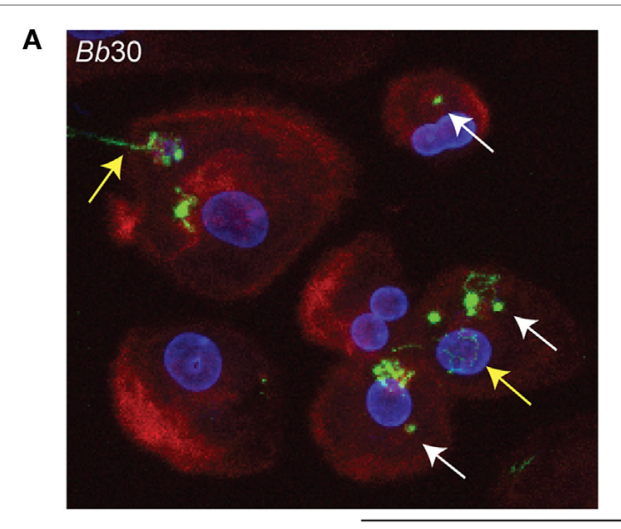

B

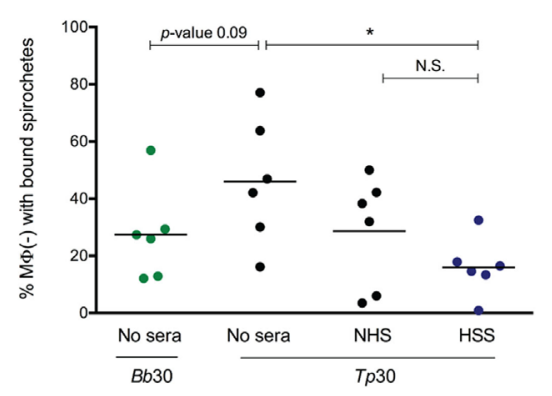

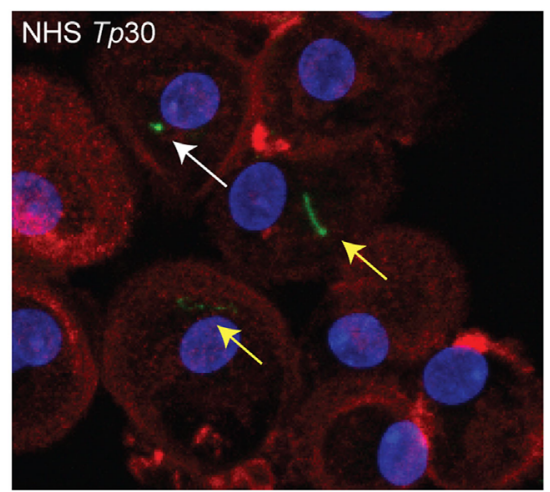

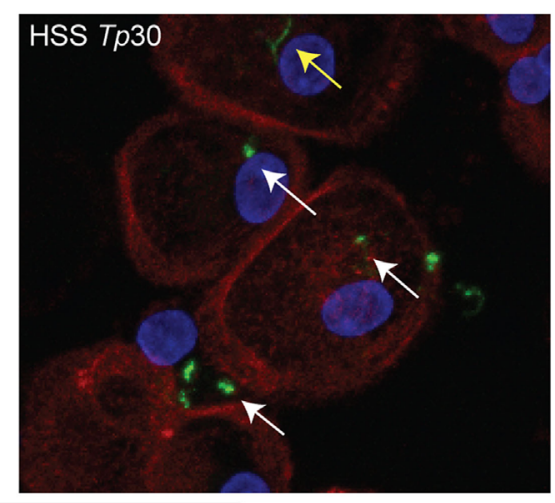

$M \Phi(-)$

C

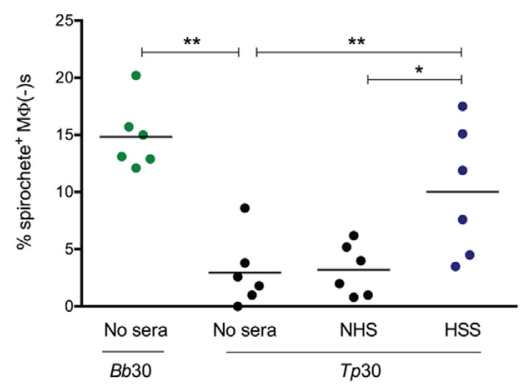

D

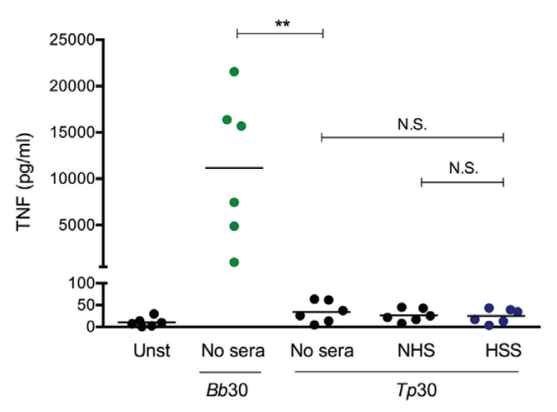

FIGURE 2 | Spirochetal uptake and cytokine secretion by primary human macrophages. Monocyte-derived macrophages [depicted as M $\Phi(-)$ ], matured with 20\% normal human serum (NHS) were stimulated with Borrelia burdorferi (Bb) or Treponema pallidum (Tp) at an multiplicity of infection (MOI) $30: 1$ for 8 h. Tp were incubated alone (no sera) or, where indicated, with 10\% heat inactivated NHS or human syphilitic serum (HSS). (A) Macrophage actin cytoskeleton (red), nucleus (blue), and Bb or Tp (green) were labeled and imaged as described in Section "Materials and Methods." Representative confocal micrographs demonstrating binding (yellow arrow) and internalization (white arrow) of spirochetes are shown as 20 consecutive compressed Z-stack panels. Dot plot in (B) shows percentage of M $\Phi(-)$ s with surface bound spirochetes in four conditions, Bb alone and Tp with no sera, NHS, or HSS. Dot plot in (C) reveals the percentage of M $\Phi(-)$ s containing internalized $\mathrm{Bb}$ and $\mathrm{Tp}$ in the presence of HSS (blue circles) when compared to no sera and NHS (black circles). Dot plot in (D) reveals supernatant TNF concentration $(\mathrm{pg} / \mathrm{ml})$ for $M \Phi(-)$ s stimulated with $B b$ (green circles) and Tp under three different conditions. Statistical significance between Bb and no Sera Tp was determined by two-tailed Mann-Whitney test. The statistical significance between the three Tp conditions was determined by Friedman's test with a Dunnett's multiple comparison post-test analysis. N.S., not significant, ${ }^{\star} p$-value of $<0.05,{ }^{\star \star} p$-value of $<0.01$.

(Figure 3A), while expression of the antigen presentation molecule HLA-DR was appreciably increased (48) (Figure 3A). CD14, a glycosylphosphatidylinositol-linked membrane glycoprotein that interacts with several pattern recognition receptors (PRRs), including TLR2 and complement receptor-3 (CR3) (42, 49-51), was upregulated by IFN $\gamma$ (Figure 3A). iNOS, notorious for its vital role in antimicrobial activity as part of the oxidative burst of macrophages, was also significantly increased by IFN $\gamma$ (Figure 3B). We also assessed macrophage expression of the scavenger receptor CD163 (52) and the C-type lectin CD206 (29), which are associated with alternative macrophage activation. CD163 and CD206 were for the most part unaffected by IFN $\gamma$ (Figure 3B). We then examined the expression of TLR2, 7, and 8 , which we have shown to be upregulated in SS skin lesions (10). Expression of TLR7 was similar between the two macrophage phenotypes. On the other hand, TLR2, which is essential for spirochetal lipoprotein recognition, and TLR8, an endosomal TLR involved in single-stranded spirochetal RNA recognition (53), were increased in response to IFN $\gamma$ (Figure 3C).
We further examined transcriptional differences between unstimulated $M \Phi(\mathrm{C})$ s and $M \Phi(\operatorname{IFN} \gamma)$ s by using a commercially available microarray panel. As shown in Table 1, several genes that code for macrophage activation markers, microbial PRRs, cytokines and chemokines, were significantly upregulated by IFN $\gamma$. Among them, the activation markers CD40 and CD80, as well as CD38, a type II transmembrane glycoprotein involved in $\mathrm{Ca}^{2+}$ signaling during Fc $\gamma \mathrm{R}$-mediated bacterial uptake (54) were transcriptionally increased. In line with the flow cytometry results shown in Figure 3, TLR2 and TLR8 were also upregulated in the arrays. PTGS2, the gene which codes for COX-2 and is associated with classically activated macrophages (44), and several inflammatory chemokines and cytokines (CXCL11, IL1B,IL1A, $I L 8, I L 15)$ involved in cellular recruitment and activation were also transcriptionally upregulated. Of particular importance, all three Fc $\gamma$ Rs (CD16, CD32, and CD64) were upregulated in $\mathrm{M} \Phi(\mathrm{IFN} \gamma)$ s. In parallel stimulation experiments, we compared proinflammatory cytokine production in response to several TLR ligands (MMP, LPS, or R848) between $M \Phi(C) s$ and $M \Phi(I F N \gamma) s$. 

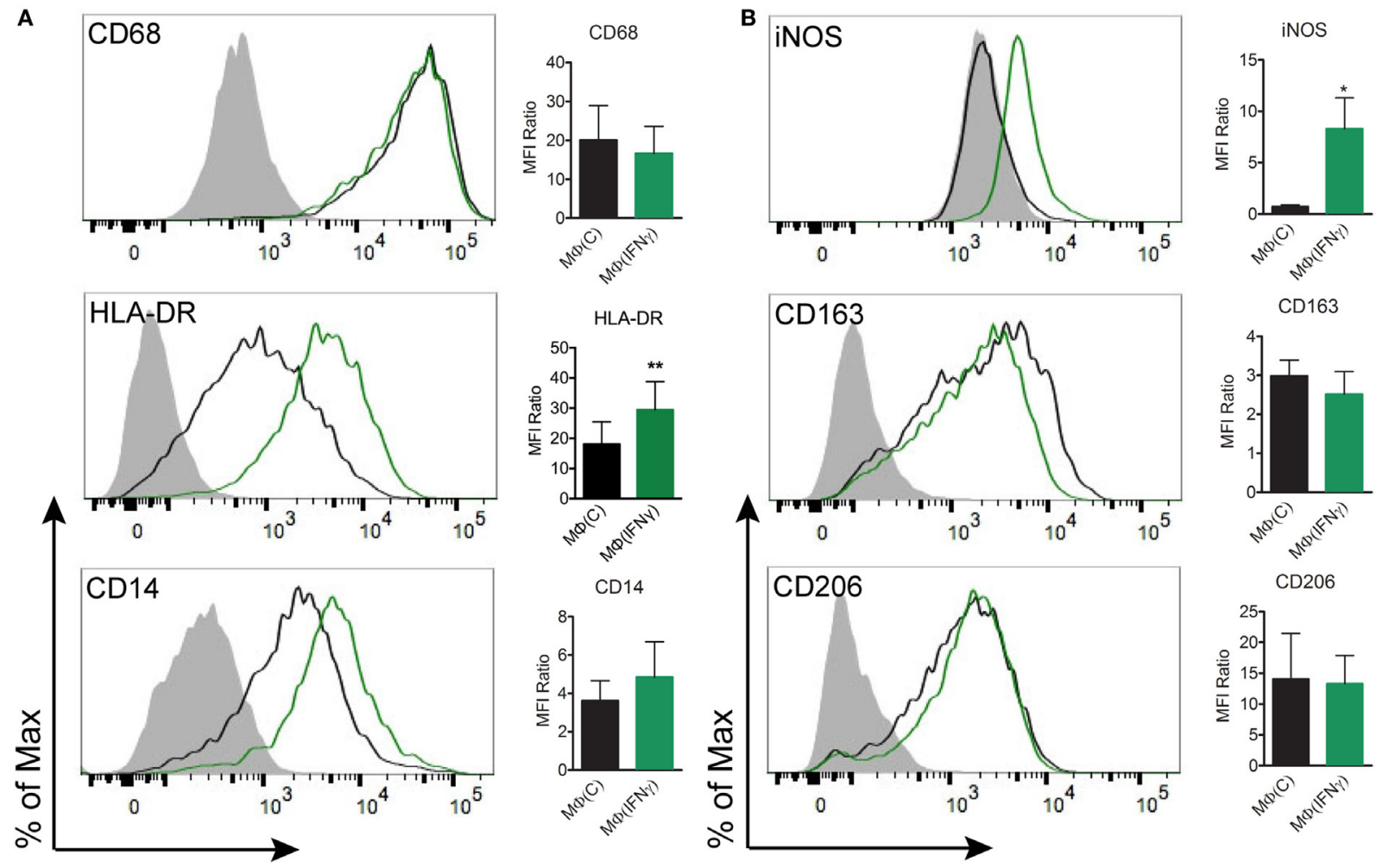

CD163
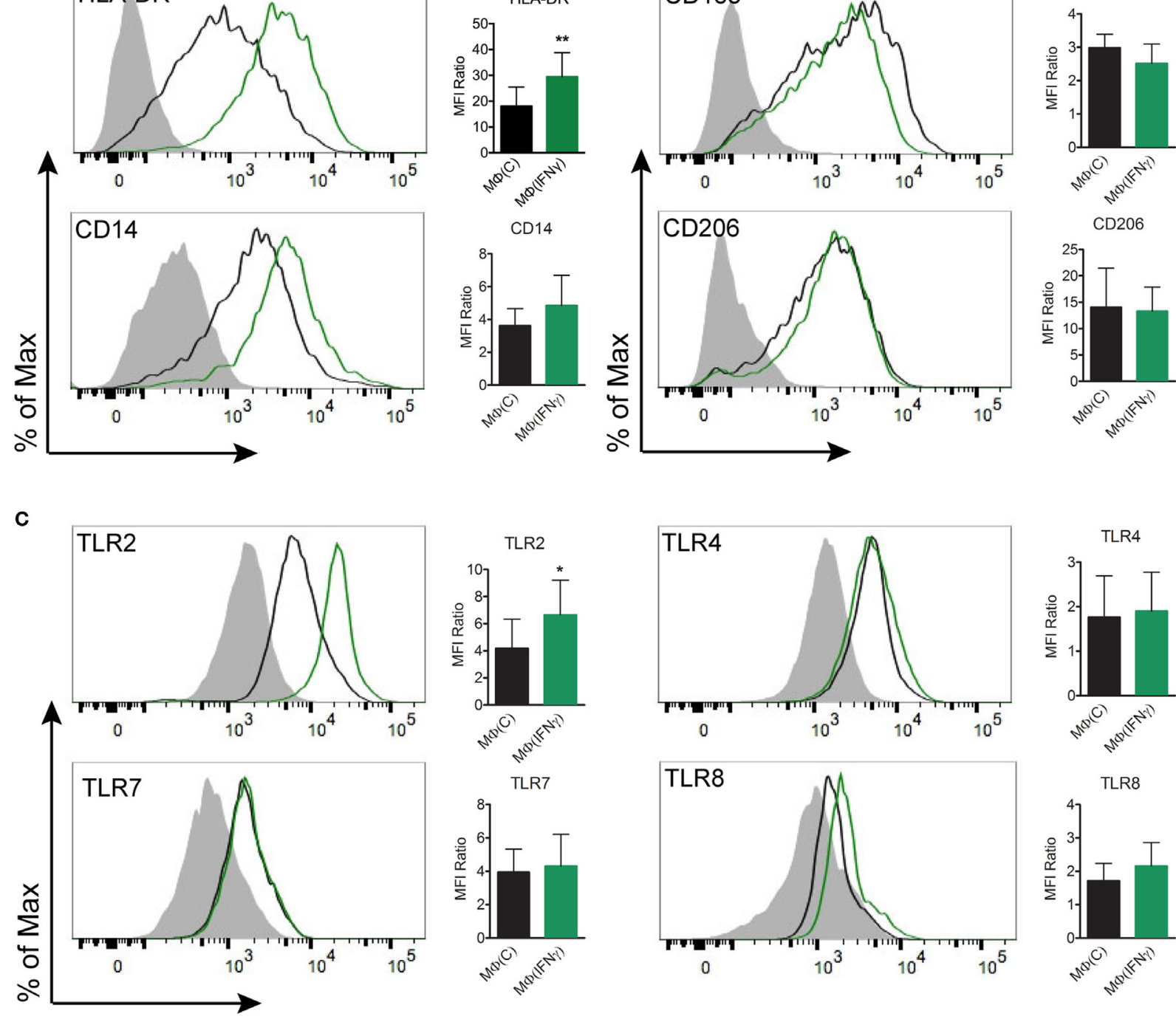

FIGURE 3 | Flow cytometric analysis of macrophage immunophenotypic profile. Monocyte-derived macrophages were generated from healthy controls by incubating monocytes with M-CSF $[\mathrm{M} \Phi(\mathrm{C})]$ for 7 days and then a portion of the macrophages were activated with IFN $[\mathrm{M} \Phi(\mathrm{IFN} \gamma)]$ for the remaining 3 days. $M \Phi(C) s$ (black) and $\mathrm{M} \Phi(\mathrm{IFN} \gamma) \mathrm{s}$ (green) from the same participant were stained for (A) macrophage markers: CD68 $1 \mathrm{lC}, \mathrm{HLA}-\mathrm{DR}, \mathrm{CD}_{14}$, (B) phenotypic markers: iNOS $\mathrm{S}_{\mathrm{IC}}$,

CD163, CD206, and (C) Toll-like receptors: TLR2, TLR4, TLR7 IC, TLR8 Ic; the filled gray histograms indicate the isotype control. Histograms are representative of a minimum of four independent experiments that were used to quantify the mean fluorescence index (MFI) ratio \pm the SD as described under Section "Materials and Methods." Paired Student's $t$-tests (Wilcoxon test) was used to determine statistical significance between the two macrophage phenotypes, ${ }^{\star} p$-value of $<0.05$, ${ }^{* *} p$-value of $<0.01$. IC, intracellular staining.

We observed that, independently of the TLR ligand used, IFN $\gamma$ primed macrophages produced significantly more cytokines than non-primed $M \Phi(C)$ s (Figure S3 in Supplementary Material).
Our combined observations thus confirm that M-CSF cultivated macrophages in the presence of IFN $\gamma$ exhibit a classically activated macrophage phenotype. 
TABLE 1 | Transcription profile of $M \Phi(\mid \mathrm{FN} \gamma)$ s.

\begin{tabular}{|c|c|c|}
\hline Gene transcript & Protein name & Average fold change \\
\hline \multicolumn{3}{|c|}{ Activation markers } \\
\hline CD38 & CD38 & 97.7 \\
\hline CD40 & CD40 & 2.0 \\
\hline CD80 & CD80 & 3.0 \\
\hline HLA-DRA & HLA-DR $\alpha$ & 14.8 \\
\hline HLA-DRB1 & HLA-DR $\beta 1$ & 8.0 \\
\hline \multicolumn{3}{|l|}{ Fc $\gamma$ receptors } \\
\hline FCGR1 & CD64 & 1.9 \\
\hline FCGR2 & CD32 & 1.4 \\
\hline FCGR3 & CD16 & 1.8 \\
\hline \multicolumn{3}{|c|}{ Toll-like receptors } \\
\hline TLR2 & TLR2 & 2.0 \\
\hline TLR6 & TLR6 & 2.9 \\
\hline TLR8 & TLR8 & 2.7 \\
\hline TLR9 & TLR9 & 3.1 \\
\hline TLR10 & TLR10 & 4.3 \\
\hline \multicolumn{3}{|l|}{ Enzymes } \\
\hline PTGS2 & COX-2 & 5.7 \\
\hline \multicolumn{3}{|c|}{ Cytokines/chemokines/growth factors } \\
\hline CSF2 & GM-CSF & 3.5 \\
\hline CSF3 & G-CSF & 9.8 \\
\hline CXCL11 & CXCL11 & 5.9 \\
\hline IL15 & $\mathrm{IL}-15$ & 6.5 \\
\hline IL $1 A$ & $\| \mathrm{L}-1 \alpha$ & 4.7 \\
\hline IL1B & $\| \mathrm{L}-1 \beta$ & 4.6 \\
\hline IL8 & IL-8 & 8.4 \\
\hline$T N F$ & TNF & 2.1 \\
\hline
\end{tabular}

Target array analysis of unstimulated $M \Phi(I F N \gamma)$ s vs. paired unstimulated $M \Phi(C) s$ $(N=6)$.

\section{IFN $\gamma$ Enhances HSS-Mediated Internalization of $T p$, Inflammatory Immune Signature, and Cytokine Production by Human Macrophages}

Having generated macrophages by closely considering the microenvironment of syphilitic skin lesions, we then asked how these cells would respond to opsonized Tp ex vivo. To address this question, we stimulated $M \Phi(\mathrm{C}) \mathrm{s}$ and $M \Phi(\operatorname{IFN} \gamma) \mathrm{s}$ with $T p$, in the presence or absence of opsonic antibodies, and assessed their phagocytic potential and immune responsiveness by confocal microscopy and cytokine production, respectively. We observed binding of the spirochete to both macrophage phenotypes, irrespective of the presence of HSS (Figure S4A in Supplementary Material). Spirochetes were seen attached to the macrophages by their tips (Figure 4A, bottom left inset-yellow arrow) and in some cases across the entire length of the bacterial surface (Figure 4A, top right inset-blue arrow). The addition of HSS led to a marked increase in phagocytosis of $T p$ by both macrophage phenotypes (Figures 4A,B), although the phagocytic index was significantly greater in IFN $\gamma$ stimulated cells (Figure 4C). In agreement with enhanced uptake of opsonized spirochetes, we recovered significantly fewer spirochetes when HSS was included in the stimulation experiments (Figure S4B in Supplementary Material). Tp stimulated $M \Phi(\operatorname{IFN} \gamma)$ s secreted more TNF (Figure 4D) and IL-6 (Figure 4E) than their counterparts without IFN $\gamma$, but neither macrophage phenotype secreted IL-1 $\beta$ (Figure 4F). Overall, these findings confirm our hypothesis that elements present within the syphilitic tissue microenvironment, specifically IFN $\gamma$, alter macrophage uptake and responsiveness to opsonized $T p$.

To further characterize the effect of opsonized $T p$ on the macrophage, we used targeted phagocytic and inflammatory transcriptional array analysis. For these experiments, the relative fold changes of gene transcripts between $T p$ stimulated and unstimulated $M \Phi(\operatorname{IFN} \gamma)$ s were measured in three experimental conditions; Tp with no sera, with NHS and with HSS (Figure 5). We first compared genes induced in Tp stimulated $M \Phi(I F N \gamma)$ $s$ with no sera or with NHS. Consistent with our findings above, where spirochetal uptake and cytokine secretion were similar between the two conditions in the absence of HSS, we observed that transcriptional profiles were also comparable, such that none of the genes met our differential expression threshold of two-fold change and $p$-value of $<0.05$ (Figure S5A in Supplementary Material). On the other hand, several genes were significantly upregulated in Tp stimulated $M \Phi(\operatorname{IFN} \gamma)$ s in the presence of HSS when compared to similarly stimulated M $\Phi(I F N \gamma)$ s with NHS (Figure S5B in Supplementary Material). CD38, CD40 and CD80 were increased, whereas the activation marker CD86 varied greatly between the individual participants (Figure 5). TLR7 was markedly increased in 5/6 healthy volunteer macrophages, but this increase was not statistically significant. TLR2 and TLR8, which have been shown to be important in spirochetal recognition $(33,53,55)$ were significantly upregulated as a result of Fc $\gamma \mathrm{R}$-mediated uptake of Tp. Given the significant upregulation of TLR8 (Figure 5) and the importance of type I IFNs in response to spirochetes $(33,56)$, in parallel RT-PCR experiments, we also assessed the expression of $I F N B$, and three interferon regulatory factors (IRFs, IRF3, IRF5, and IRF7) by RT-PCR. We observed no change in expression of IRF3 and IRF5 (Figure S5C in Supplementary Material). IRF7 was significantly upregulated, but we did not detect a substantial change in IFNB expression (Figure S5D in Supplementary Material).

We observed that many cytokine and chemokines involved in cellular recruitment as well as induction of other physiological responses, including enhanced phagocytosis, were differentially regulated in $T p$ stimulated $M \Phi(I F N \gamma) s$ in the presence of HSS. Among them, granulocyte macrophage colony-stimulating factor (GM-CSF), which is encoded by CSF2 and has been described to trigger the differentiation and exiting of monocytes from the bone marrow was upregulated. There was a strong induction of chemotactic factors, including CXCL10 and CXCL11, which are important for recruitment of monocytes/macrophages to the site of infection. $I L 12 B$, which is known to stimulate T cells and NK cells to secrete IFN $\gamma$, was robustly increased in $5 / 6$ healthy volunteer macrophages. The transcript for IL15 (Figure 5), a strong NK cell activating cytokine (57), was also elevated. Although IL-1 $\beta$ protein was not secreted by the macrophages following $T p$ stimulation (Figure 4D), IL1B was transcriptionally upregulated (Figure 5). The findings together suggest that neither Tp nor its PAMPs, escape the phagosome into the cytosol to induce caspase activation and cleavage of pro-IL- $1 \beta$ into the active cytokine in accord with the mechanism detailed by Netea et al. (58). 


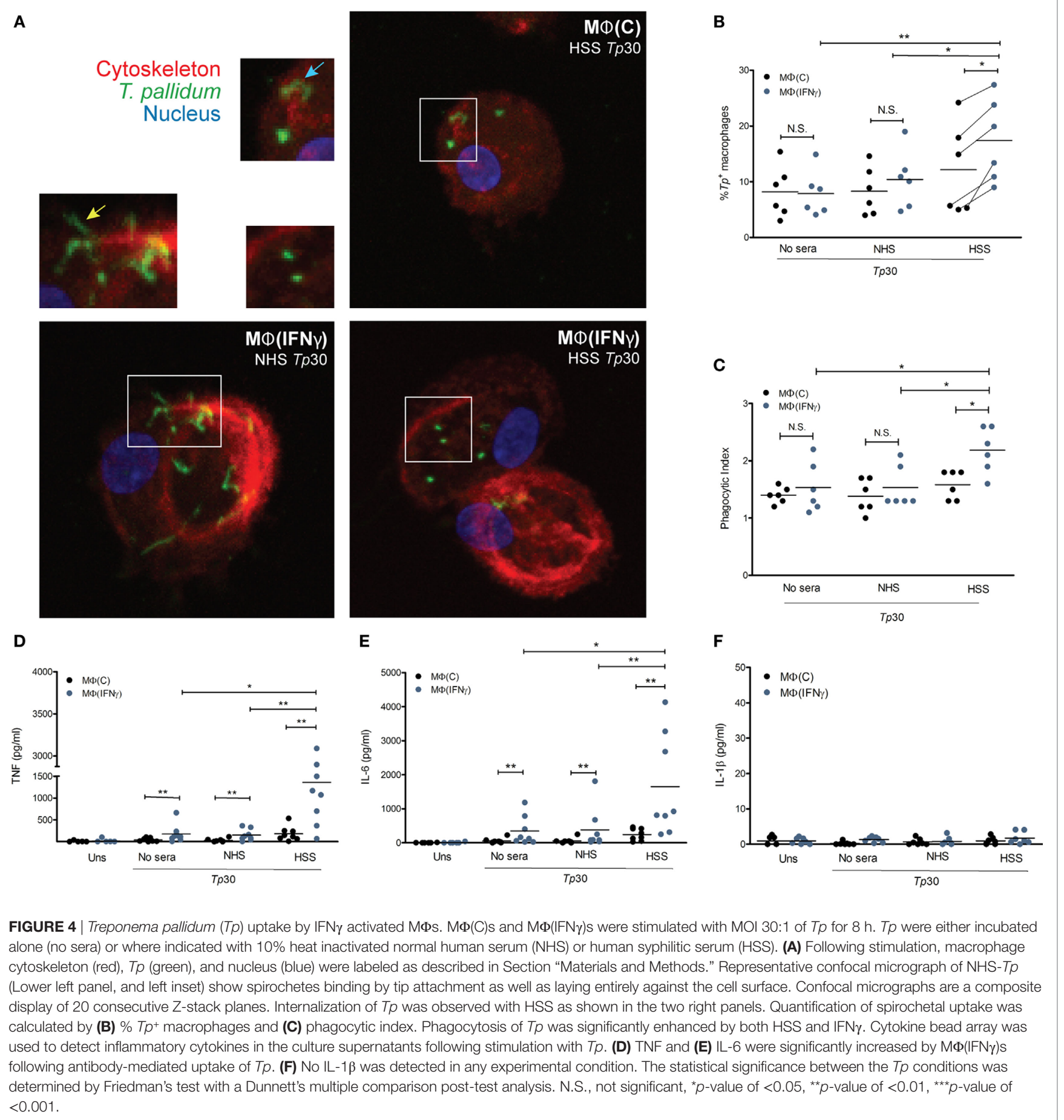

\section{CD64 Is Primarily Responsible for Macrophage Driven Opsonophagocytosis of $T p$}

Fcy receptors have been observed to be upregulated in syphilitic skin lesions by transcriptional analysis (10) and are important for binding of IgG with various receptor-ligand affinities (59). Based on our primary human macrophage data (Figures 2A and 4A) and published studies $(10,12,19,23)$ demonstrating the importance of HSS in spirochetal uptake, we hypothesized that Fc $\gamma$ Rs are the major phagocytic receptors for $T p$. To study this premise, we first assessed the effect of IFN $\gamma$ on CD16, CD32, and CD64 expression by flow cytometry. Expression of CD16 (FcyRIII), which weakly binds IgG (59), was only mildly affected by IFN $\gamma$, while expression of CD32 (FcyRII), another low affinity IgG binder, was not affected (Figure 6A). Conversely, expression of CD64 (FcyRI), a high affinity receptor which binds $\operatorname{IgG}$, specifically $\operatorname{IgG}_{1}$ and $\operatorname{IgG}_{3}(59)$, was significantly upregulated by IFN $\gamma$ (Figures 6A,B). 


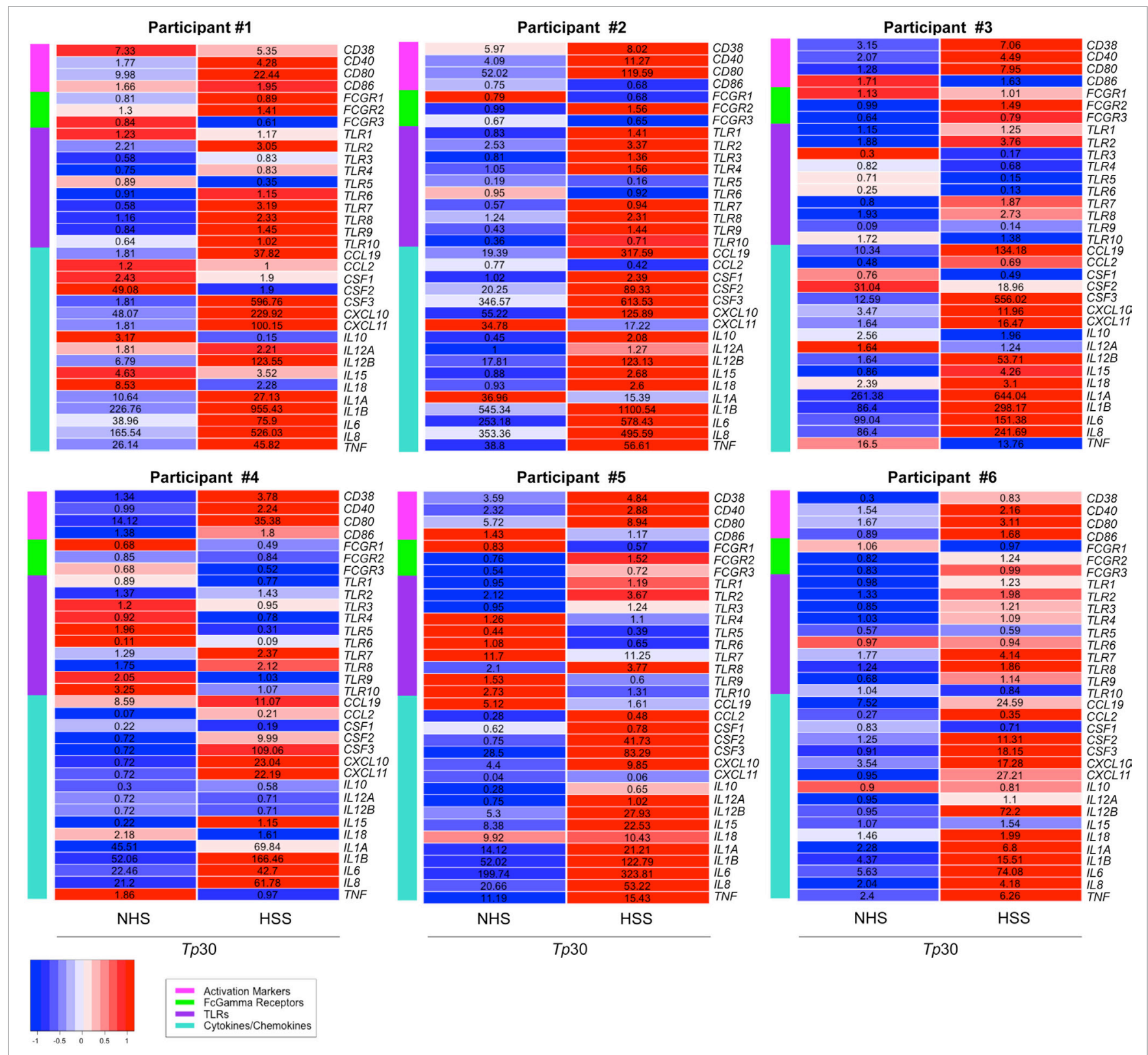

FIGURE 5 | Transcriptional profile of M $\Phi($ IFN $\gamma)$ stimulated with Treponema pallidum (Tp). Transcription profiles were determined by targeted array transcriptional analysis after stimulation of $\mathrm{M} \Phi(\mathrm{IFN} \gamma)$ s with unopsonized [no sera or normal human serum (NHS)] or opsonized [human syphilitic serum (HSS)] Tp (MOI $30: 1)$ for $8 \mathrm{~h}$ in six-well tissue culture treated plates. Relative fold changes were normalized to the unstimulated $M \Phi(I F N \gamma)$ s control for each gene and then heat maps were generated based on gene categories of interest: activation markers, Fc $\gamma$ receptors (FcyRs), TLRs, and cytokines/chemokines. Heat maps depict the Z-score of NHS-Tp30 and HSS-Tp30, based on comparing all stimulation conditions, with relative fold-changes values in corresponding gene panel. Each heat map represents an $N=1$ for individual participants, from a total of six independent experiments.

Due to the significant increase in CD64 expression induced by IFN $\gamma$ (Figure 6A) and importance of syphilitic serum in spirochetal uptake (Figure 4C), we then assessed the localization of CD64 with both unopsonized and opsonized Tp by confocal microscopy. CD64 could be seen localizing with unopsonized $T p$ (Figure 7A, middle right) however when the spirochetes were opsonized with HSS, the intensity of the colocalization was more robust and is most likely a result of Fc $\gamma$ Rs clustering to the site of treponeme attachment (Figure 7A, lower right). To determine the role of Fc $\gamma$ Rs in spirochetal uptake, we used monoclonal antibodies against human CD16, CD32, and CD64 to block the interaction between opsonized spirochetes and each of the three Fc receptors and then compared bacterial uptake and inflammatory cytokine production between blocked and unblocked M $($ IFN $\gamma)$ s. As shown in Figure 7B, there were no significant reductions in uptake by blocking CD16 or CD32. 


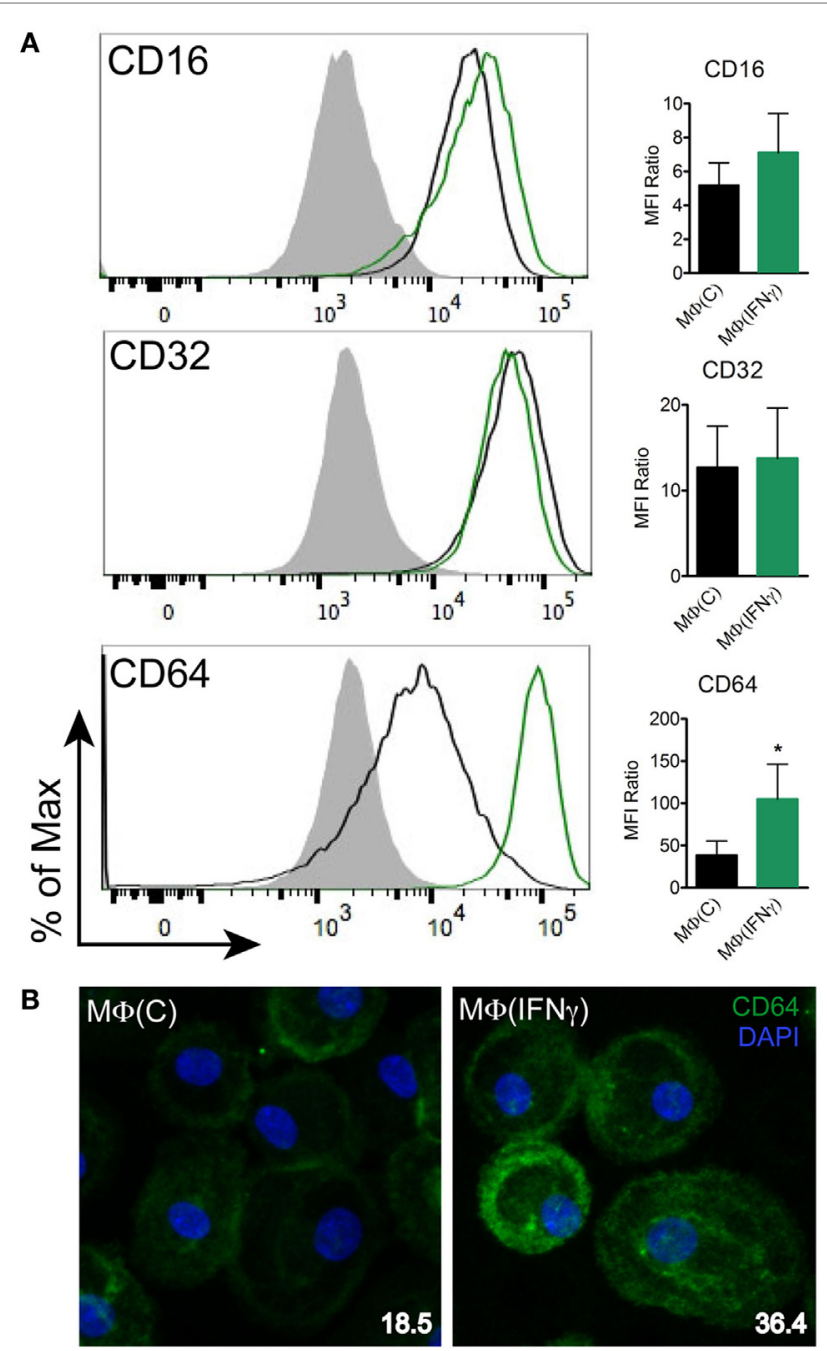

FIGURE 6 | CD64 expression on human macrophages. MФ(C)s (black) and $M \Phi(I F N \gamma) s$ (green) from the same participant were assessed to determine the expression level of (A) Fc $\gamma$ receptors (FcyRs): CD16, CD32, and CD64 by flow cytometry. The filled gray histograms indicate the isotype control. Histograms are representative of a minimum of four independent experiments. Data of the mean fluorescence intensity (MFI) ratio \pm the SD were analyzed for statistical significance using the paired Student's $t$-test, ${ }^{*} p$-value of $<0.05$. (B) $M \Phi(C)$ s and $M \Phi(I F N \gamma)$ s were incubated in eight-well chamber slides and expression of CD64 (green) was determined by IFA with mouse anti-human CD64 (clone 10.1) antibody. Representative confocal micrographs of CD64 expression levels shown as a composite of 10 consecutive Z-stack planes. CD64 MFI values (inset in bottom right) were calculated using ImageJ.

However, blockade of CD64 did cause a significant decrease in phagocytosis of opsonized spirochetes (Figure 7B), as well as TNF production (Figure 7C). This finding was not surprising because IgG1 and IgG3, the prominent IgG subclasses in syphilitic serum (60), are high affinity IgG subclasses known to bind CD64. Importantly, the use of monoclonal antibodies against CD64 alone, or in combination with CD16 and CD32, did not result in complete abrogation of phagocytosis (Figure $7 \mathbf{B}$ ), suggesting that additional phagocytic receptors could have a role in Tp uptake. Taken together, these data show for the first time that CD64 acts as the primary phagocytic receptor for Fc $\gamma$ R-mediated uptake of opsonized $T p$, and that IFN $\gamma$-mediated enhanced expression of CD64 promotes Fc-receptor-ligand interactions.

\section{DISCUSSION}

Much of what is currently known about the role of the macrophage in syphilis pathogenesis emanates from several decades of in vivo and ex vivo studies using the rabbit model of infection $(15,16,19$, 20, 22, 61-63). Lukehart and Miller (19) demonstrated that chemically activated rabbit peritoneal macrophages phagocytose $T p$ ex vivo in the presence of syphilis immune rabbit sera. This landmark study was the first to underscore the importance of the macrophage in Ab-mediated uptake of the syphilis spirochete. Additional rabbit studies established that clearance of the spirochete in vivo temporally correlates with the influx of macrophages to infected tissues $(15,16,64)$ and generation of a "lymphocyte factor" (65), now known to be IFN $\gamma$ (18). Although the rabbit model has proved to be an important resource in syphilis research, humans are the obligate host for Tp. Thus, it is critical to develop an ex vivo human model to aid in understanding the immunological responses of the natural host evoked by the bacterium. Studies to understand the role of the macrophage in human syphilis have relied on a combination of transcriptional and IHC analysis of early syphilitic lesions and are only now being explored with an ex vivo macrophage system. Only a handful of studies have evaluated human monocyte/macrophage- $T p$ interactions ex vivo $(10,12,23)$. In one such study, our group showed that HSS promotes spirochetal uptake by isolated human monocytes, leading to destruction of the bacterium within phagosomal vacuoles and enhanced secretion of proinflammatory cytokines (i.e., TNF) (10). Recently Marra et al. described that $20-47 \%$ of monocytederived-human macrophages internalized HSS opsonized spirochetes (23). However, the researchers did not assess the impact of the macrophage phenotype in phagocytosis or the inflammatory response elicited to the bacterium. The immunological environment provides critical information when developing a model system because macrophage phenotypic plasticity and polarization ex vivo are highly dependent on the cytokines and growth factors used in the differentiation protocols $(28,44,52,66)$. We elected to carefully model the immunologic niche where macrophage- $T p$ interactions are likely to occur under actual disease conditions for our system. We observed that the addition of IFN $\gamma$ enhanced the macrophage's phagocytic capacity for opsonized spirochetes, as well as the secretion of inflammatory cytokines. Unlike the rabbit model, where $63-76 \%$ of the macrophages contained ingested opsonized spirochetes (19), the human system resulted in a much lower \% of $\mathrm{Tp}^{+}$cells and confirms the variability of uptake described by Marra et al. (23). We feel this result observed in the ex vivo macrophage system more accurately reflects the true duality of the disease; this duality can be observed in Figure 1, where treponemes appear to be migrating to locations that are difficult for the immune cells such as $\mathrm{CD}^{+} 8^{+}$macrophages to access, while increasing the odds for bacterial transmission. 


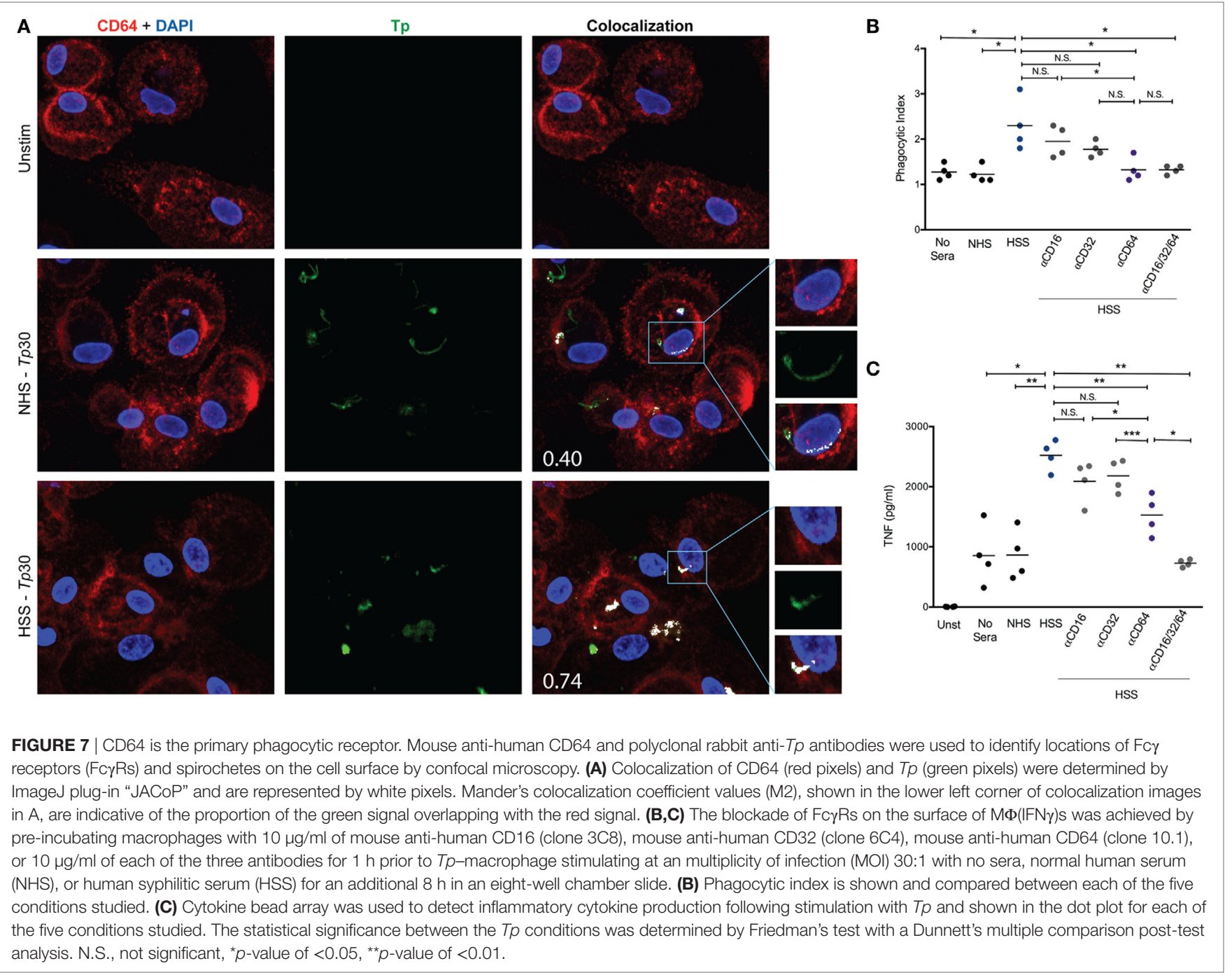

Our study results reinforce our underlying hypothesis that macrophage differentiation is an important factor for optimal treponemal recognition. In the presence of M-CSF and IFN $\gamma$ macrophages exhibited a "classically activated" phenotype (67) and responded to opsonized $T p$ by secreting large quantities of TNF. By comparison, while non-IFN $\gamma$ stimulated macrophages were also capable of internalizing opsonized spirochetes, their cytokine responsiveness was markedly decreased. The difference in cytokine responses between the two macrophage phenotypes has several potential explanations. First, IFN $\gamma$ induced expression of CD64 is likely to engender more efficient uptake of opsonized spirochetes, which translates into an increase in bacterial cargo available for signaling from within the phagosome. Second, upregulation of baseline TLR2 and TLR8 expression by IFN $\gamma$, as shown herein, could promote more opportunities for ligation of released spirochetal PAMPs $(33,53)$ and TLR signaling itself may lead to a more rapid maturation of the phagosome (68). Alternatively, as shown by Balce et al. (69) FcyR-mediated phagocytosis in association with IFN $\gamma$ could facilitate phagosomal processing of proteins. IFN $\gamma$ stabilizes MyD88 (70), in addition to modulation of the $\mathrm{F} c \gamma \mathrm{R}$ signaling cascade $(59,71)$, helping to enhance the recognition response to $T p$. Intriguingly, a similar decrease in cytokine production was not seen in non-IFN $\gamma$ primed $B b$-stimulated macrophages. Several reasons likely account for the differential response between $B b$ and $T p$. Although both spirochetes contain lipoproteins known to signal through TLR2 $(33,55,72), B b$ is larger in size than $T p$ and has a far richer repertoire of lipoproteins within its outer and inner membranes. In addition, $B b$ 's nucleic acid is far more abundant and complex than $T p$ 's, thus nucleic acid ligands are likely to have more opportunities to engage their cognate endosomal TLR receptors (i.e., TLR8). Ultimately, macrophages phagocytose $B b$ directly via the phagocytic receptor CR3 $(42,73)$. The process does not require the presence of complement or opsonic antibodies, leads to efficient uptake of the bacterium and activation of phagosomal receptors despite the absence of IFN $\gamma$.

Macrophage recognition of a bacterial pathogen is a very dynamic and complex process that involves a variety of receptors and is greatly influenced by the molecular composition and structure of the organism they encounter. Although $T p$ contains 
an abundance of highly antigenic hydrophilic polypeptides, these molecules are tethered by covalently bound N-terminal lipids to the bacterium's periplasmic inner membrane leaflet and thus not available for innate immune receptor (i.e., TLR1/2) sensing (74-76). In addition, because Tp contains very few OMPs $(77,78)$, the bacterium provides limited binding sites for syphilitic opsonic antibodies (79). Nevertheless, our study demonstrates that HSS is able to opsonize Tp and lead to FcyR-mediated uptake by human macrophages, where CD64 acts as the primary phagocytic receptor. The Tp-specific antibodies generated by the host, are primarily comprised of IgG1 and IgG3 subclasses (60), are known to bind to CD64 with high affinity (59). Clustering of CD64, as demonstrated occurs in the presence of opsonized spirochetes (Figure 7A), initiates important signal transduction events that result in internalization of the pathogen (80). Although receptor dimerization can be sufficient for receptor activation, beads coated with low densities of IgG, similar to what occurs with $T p(77,79)$, trigger inefficient receptor recruitment, thus slowing formation of the phagocytic cup (81). The heterogeneity of antibodies binding to spirochetal populations (79), in combination with the low density of OMPs (77) and fixed locations of the antigenic targets (78) may contribute directly to the slow phagocytic events of the treponemes previously described $(82,83)$. They may also explain why a large proportion of spirochetes are capable of avoiding opsonophagocytosis (Figure S3B in Supplementary Material). IFN $\gamma$-enhanced expression of CD64 most likely engenders more efficient uptake of opsonized spirochetes and inflammatory responses, which allow the human host to override the gridlock caused by the organisms unique OM structure and requirement of opsonic antibodies to eventually clear the pathogen.

Following opsonophagocytosis of a delicate pathogen, such as $T p$, the acidic environment of the phagosomal vacuole disrupts the spirochete's OM (12). Liberation of once concealed spirochetal PAMPs makes them accessible to interact with their cognate receptors and initiate downstream inflammatory signals. Herein, we demonstrate that in addition to NF- $\mathrm{KB}$ mediated cytokine production, opsonized $T p$ induces transcription of type I interferons, several chemokines, and many other inflammatory mediators. Among them is IFN- $\beta$, a type I interferon known to be present in SS skin lesions (10), which we believe is triggered similarly to $B b$, via a TLR8-IRF7 pathway (53). The chemokines CCL19, CXCL10, and CXCL11, are chemokines associated with recruitment of DCs, antigen engaged B cells, NK cells, and activated T cells to infected tissues (84-86) were differentially transcribed following uptake of opsonized Tp, and were upregulated in SS skin lesions (10). IL-12 and IL-15, two cytokines secreted by macrophages and associated with activation of T cells and NK cells (57), were also transcriptionally modulated. Interestingly, activated NK cells and $\mathrm{CD}^{+} \mathrm{T}$ cells, known for production of IFN $\gamma$ in response to $\mathrm{Tp}$ $(12,14)$, are typically associated with degranulation in response to viral infection and tumor cells $(87,88)$ but $T p$ is an extracellular pathogen. The immunological functions elicited by $\mathrm{CD}^{+}$ T cells and NK cells in the syphilitic lesions are unclear, with the

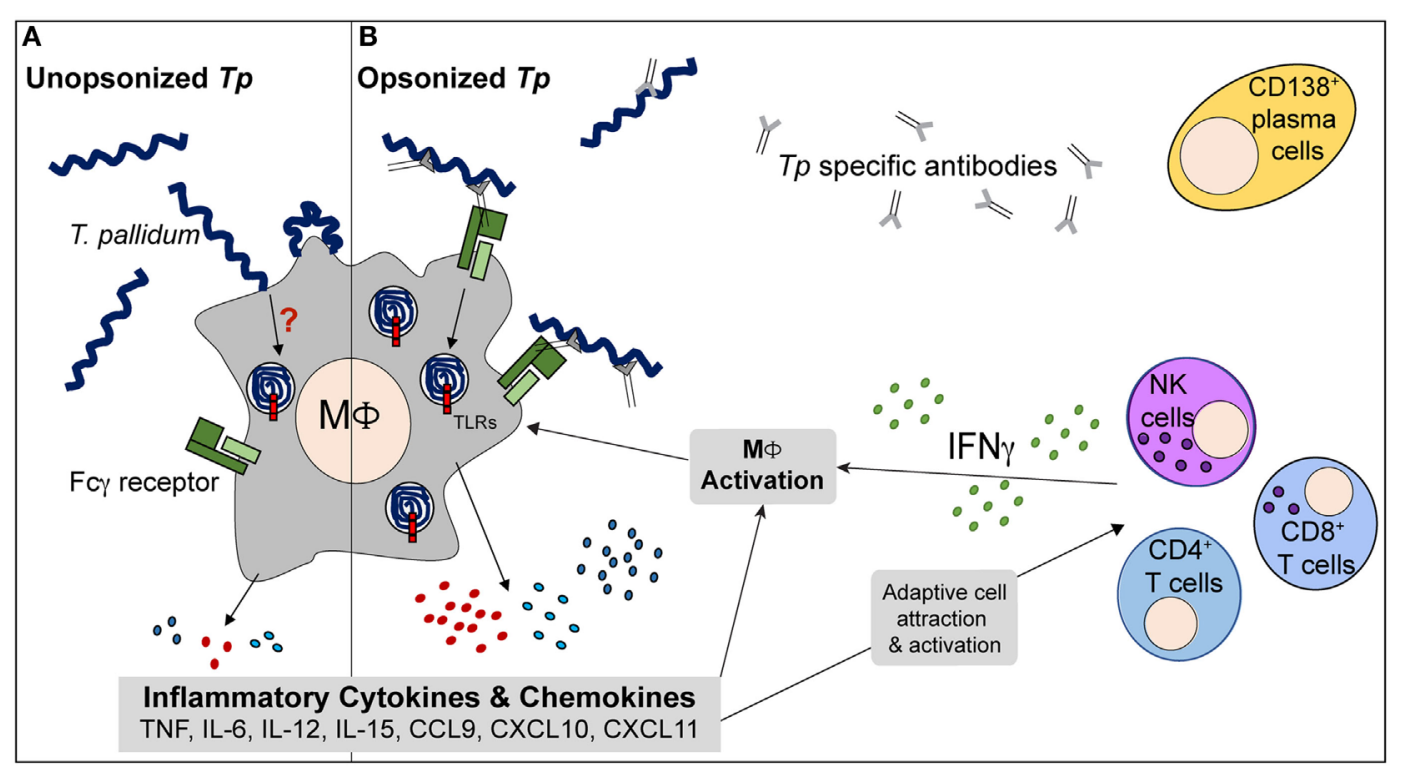

FIGURE 8 | Proposed model of immune interplay in secondary syphilis (SS) lesions. (A) During early response to Tp, human macrophages (Mథs) are able to bind unopsonized spirochetes but the cells phagocytose very limited numbers and many $T p$ are able to escape. The phagocytic process is inefficient and results in minimal inflammatory cytokine production. (B) Following antigen presentation by phagocytes, lymphocytes such as $C D 4^{+} T$ cells, CD8 ${ }^{+} T$ cells, and NK cells produce IFNy locally. T cell activation can aid in B cell maturation and Tp specific Ab production. The antibodies are directed to various targets of the treponemes, including

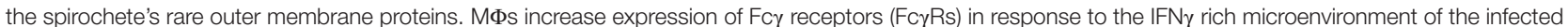
tissue and allow for enhanced phagocytosis of opsonized treponemes. Within the MФs' phagosomal compartment, the spirochetes' fragile outer membrane is degraded, liberating the once concealed pattern-associated molecular patterns (PAMPs) and ultimately resulting in interaction with TLRs, such as TLR2 and TLR8. The activated MФs produce elevated levels of inflammatory cytokines (TNF, IL-12, and IL-15) and chemokines, resulting in an important positive feedback loop that acts on both branches of the immune system. Ultimately, with aid from the adaptive immune system, the macrophage plays a central role in clearance of $T p$. 
exception of sourcing IFN $\gamma$ for macrophage activation. It is also possible that macrophages are presenting antigen to $\mathrm{T}$ cells via a cross presentation mechanism and that other lymphocytes are involved in macrophage-independent mechanisms of clearance in the tissues. In short, it is clear that in the context of phagosomal signaling, the macrophage plays a fundamental role in generating proinflammatory signals in response to $T p$, and also modulates innate and adaptive immune responses.

Venereal syphilis can be considered a battle between the ability of $T p$ to circumvent immune recognition and the proficiency of the host's innate and adaptive immune responses to search and destroy the spirochetal pathogen $(38,39,89)$. Our results reinforce the importance of the human macrophage as a contributor in the innate immune response to $T p$. They also offer new evidence that the balance between phagocytic uptake of the spirochete and the bacterium's ability to evade immune recognition by the macrophage is significantly influenced by the emergence of anti-treponemal opsonic antibodies, as well as the immune microenvironment where the macrophage resides. More specifically, our findings provide unequivocal confirmation that HSS markedly enhances uptake of spirochetes by human macrophages in vitro. Of particular noteworthiness, our study is the first to show that in human macrophages CD64 is the primary receptor during Fc $\gamma \mathrm{R}$-mediated phagocytosis of Tp. Results from this study also substantiate the importance of IFN $\gamma$-mediated macrophage activation as a beneficial immune event that tips the balance of the battle with the spirochete in favor of the host. These findings allow us to build upon the model initially proposed by Lukehart (90) for the role of the human macrophage in the immunologic events that take place in the context of early syphilitic infection in humans. As shown in the model (Figure 8), phagocytosis by macrophages is central to the immune response against $T p$ and greatly influenced by $\mathrm{Ab}$ production to specific antigenic epitopes and production of IFN $\gamma$. The model proposes that following a prolonged period of time, and many struggles to gain control of the spirochete, macrophage-dependent and -independent immune responses ultimately lead to clearance of Tp from infected tissues. Our study also indicates the potential challenges faced in the development of a vaccine against a unique bacterium that avoids host recognition. Comprehensive analysis of confirmed OMPs such as TprC, TprD, and Tp0326 by our group $(75,76,91)$ in addition to other proteins identified by other researchers (92-94), will be critical to better understand the surface-exposed antigenic loops of $T p$ that antibodies utilize for opsonization. Lastly, our ex vivo human macrophage model will provide researchers with the first human system to assess surrogate markers for syphilis vaccine candidates.

\section{REFERENCES}

1. LaFond RE, Lukehart SA. Biological basis for syphilis. Clin Microbiol Rev (2006) 19:29-49. doi:10.1128/CMR.19.1.29-49.2006

2. Radolf JD, Tramont EC, Salazar JC. Syphilis (Treponema pallidum). 8th ed. In: Bennett JE, Dolin R, Blaser MJ, editors. Mandell, Douglas and Bennett's Principles and Practice of Infectious Disease. Philadelphia: Churchill Livington Elsevier (2014). p. 2684-709.

3. Korenromp EL, Wi T, Resch S, Stover J, Broutet N. Costing of National STI Program implementation for the global STI control strategy for the health

\section{ETHICS STATEMENT}

This study was carried out in accordance with the recommendations of the Institutional Review Boards at UConn Health, Farmington CT and Centro Internacional de Entrenamiento e Investigaciones Médicas (CIDEIM) in Cali, Colombia. All study participants were provided written informed consent. All animal experimentation was conducted following the Guide for the Care and Use of Laboratory Animals (8th Edition) and in accordance with protocols reviewed and approved by the UConn Health Institutional Animal Care and Use Committee under the auspices of Animal Welfare Assurance A347-01.

\section{AUTHOR CONTRIBUTIONS}

All authors contributed to the conception, design, and analysis of experiments. $\mathrm{KH}, \mathrm{AC}, \mathrm{CLV}, \mathrm{ML}, \mathrm{LR}$, and DM performed the experiments in the manuscript. $\mathrm{KH}$, JR, and JS wrote the manuscript. All authors critically reviewed the manuscript for intellectual content.

\section{ACKNOWLEDGMENTS}

We gratefully acknowledge all of the individuals that participated in the study. We thank the UConn Health Clinical Research Center for help with patient recruitment and appreciate Dr. Richard Cartun's assistance with the IHC analysis of the SS skin biopsies. Additionally, we appreciate Dr. Zhu Wang's support with statistical analysis of the data.

\section{FUNDING}

This work was supported by NIAID grants AI0901656 (JS), AI26756 (JR) and AI29735 (JR and MC), CCMC Arrison and Burr Curtis Research funds (JS), the Fogarty/NIH grant RO3TW009172 (AC), the Colciencias grant 222956933229 (AC), the Robert E. Leet and Clara Guthrie Patterson Trust, Bank of America, N.A., Trustee $(\mathrm{KH})$ and the research funds generously provided by Connecticut Children's Medical Center (JR and MC).

\section{SUPPLEMENTARY MATERIAL}

The Supplementary Material for this article can be found online at http://journal.frontiersin.org/article/10.3389/fimmu.2017.01227/ full\#supplementary-material.

sector, 2016-2021. PLoS One (2017) 12:e0170773. doi:10.1371/journal. pone. 0170773

4. Patton ME, Su JR, Nelson R, Weinstock H; Centers for Disease Control and Prevention (CDC). Primary and secondary syphilis - United States, 2005-2013. MMWR Morb Mortal Wkly Rep (2014) 63:402-6.

5. Centers for Disease, C. Sexually Transmitted Disease Surveillance 2014. Atlanta: U.S. Department of Health and Human Services (2015).

6. Tosca A, Lehou J, Hatjivasiliou M, Varelzidis A, Stratigos JD. Infiltrate of syphilitic lesions before and after treatment. Genitourin Med (1988) 64:289-93. 
7. Engelkens HJ, Ten Kate FJ, Judanarso J, Vuzevski VD, Van Lier JB, Godschalk JC, et al. The localisation of treponemes and characterisation of the inflammatory infiltrate in skin biopsies from patients with primary or secondary syphilis, or early infectious yaws. Genitourin Med (1993) 69:102-7.

8. Rysgaard C, Alexander E, Swick BL. Nodular secondary syphilis with associated granulomatous inflammation: case report and literature review. J Cutan Pathol (2014) 41:370-9. doi:10.1111/cup.12293

9. McBroom RL, Styles AR, Chiu MJ, Clegg C, Cockerell CJ, Radolf JD. Secondary syphilis in persons infected with and not infected with HIV-1: a comparative immunohistologic study. Am J Dermatopathol (1999) 21:432-41. doi:10.1097/00000372-199910000-00005

10. Cruz AR, Ramirez LG, Zuluaga AV, Pillay A, Abreu C, Valencia CA, et al. Immune evasion and recognition of the syphilis spirochete in blood and skin of secondary syphilis patients: two immunologically distinct compartments. PLoS Negl Trop Dis (2012) 6:e1717. doi:10.1371/journal.pntd.0001717

11. van Voorhis WC, Barrett LK, Koelle DM, Nasio JM, Plummer FA, Lukehart SA. Primary and secondary syphilis lesions contain mRNA for Th1 cytokines. J Infect Dis (1996) 173:491-5. doi:10.1093/infdis/173.2.491

12. Moore MW, Cruz AR, Lavake CJ, Marzo AL, Eggers CH, Salazar JC, et al. Phagocytosis of Borrelia burgdorferi and Treponema pallidum potentiates innate immune activation and induces gamma interferon production. Infect Immun (2007) 75:2046-62. doi:10.1128/IAI.01666-06

13. Salazar JC, Cruz AR, Pope CD, Valderrama L, Trujillo R, Saravia NG, et al. Treponema pallidum elicits innate and adaptive cellular immune responses in skin and blood during secondary syphilis: a flow-cytometric analysis. J Infect Dis (2007) 195:879-87. doi:10.1086/511822

14. Stary G, Klein I, Bruggen MC, Kohlhofer S, Brunner PM, Spazierer D, et al. Host defense mechanisms in secondary syphilitic lesions: a role for IFNgamma-/IL-17-producing CD8+ T cells? Am J Pathol (2010) 177:2421-32. doi:10.2353/ajpath.2010.100277

15. Baker-Zander S, Sell S. A histopathologic and immunologic study of the course of syphilis in the experimentally infected rabbit. Demonstration of long-lasting cellular immunity. Am J Pathol (1980) 101:387-414.

16. Lukehart SA, Baker-Zander SA, Lloyd RM, Sell S. Characterization of lymphocyte responsiveness in early experimental syphilis. II. Nature of cellular infiltration and Treponema pallidum distribution in testicular lesions. J Immunol (1980) 124:461-7.

17. Godornes C, Leader BT, Molini BJ, Centurion-Lara A, Lukehart SA. Quantitation of rabbit cytokine mRNA by real-time RT-PCR. Cytokine (2007) 38:1-7. doi:10.1016/j.cyto.2007.04.002

18. Leader BT, Godornes C, Vanvoorhis WC, Lukehart SA. CD4+ lymphocytes and gamma interferon predominate in local immune responses in early experimental syphilis. Infect Immun (2007) 75:3021-6. doi:10.1128/IAI.01973-06

19. Lukehart SA, Miller JN. Demonstration of the in vitro phagocytosis of Treponema pallidum by rabbit peritoneal macrophages. J Immunol (1978) 121:2014-24.

20. Baker-Zander SA, Lukehart SA. Macrophage-mediated killing of opsonized Treponema pallidum.J InfectDis (1992) 165:69-74.doi:10.1093/infdis/165.1.69

21. Lukehart SA, Shaffer JM, Baker-Zander SA. A subpopulation of Treponema pallidum is resistant to phagocytosis: possible mechanism of persistence. J Infect Dis (1992) 166:1449-53. doi:10.1093/infdis/166.6.1449

22. Baker-Zander SA, Shaffer JM, Lukehart SA. Characterization of the serum requirement for macrophage-mediated killing of Treponema pallidum ssp. pallidum: relationship to the development of opsonizing antibodies. FEMS Immunol Med Microbiol (1993) 6:273-9. doi:10.1111/j.1574-695X.1993. tb00339.x

23. Marra CM, Tantalo LC, Sahi SK, Dunaway SB, Lukehart SA. Reduced Treponema pallidum-specific opsonic antibody activity in HIV-infected patients with syphilis. J Infect Dis (2016) 213:1348-54. doi:10.1093/infdis/ jiv591

24. Buffet M, Grange PA, Gerhardt P, Carlotti A, Calvez V, Bianchi A, et al. Diagnosing Treponema pallidum in secondary syphilis by PCR and immunohistochemistry. J Invest Dermatol (2007) 127:2345-50. doi:10.1038/sj.jid. 5700888

25. Quatresooz P, Pierard GE. Perivascular cuff and spread of Treponema pallidum. Dermatology (2009) 219:259-62. doi:10.1159/000239970

26. Strieder LR, Leon JE, Carvalho YR, Kaminagakura E. Oral syphilis: report of three cases and characterization of the inflammatory cells. Ann Diagn Pathol (2015) 19:76-80. doi:10.1016/j.anndiagpath.2015.01.003
27. Eggers $\mathrm{CH}$, Caimano MJ, Radolf JD. Sigma factor selectivity in Borrelia burgdorferi: RpoS recognition of the ospE/ospF/elp promoters is dependent on the sequence of the -10 region. Mol Microbiol (2006) 59:1859-75. doi:10.1111/j.1365-2958.2006.05066.x

28. Murray PJ, Allen JE, Biswas SK, Fisher EA, Gilroy DW, Goerdt S, et al. Macrophage activation and polarization: nomenclature and experimental guidelines. Immunity (2014) 41:14-20. doi:10.1016/j.immuni.2014.06.008

29. Jaguin M, Houlbert N, Fardel O, Lecureur V. Polarization profiles of human M-CSF-generated macrophages and comparison of M1-markers in classically activated macrophages from GM-CSF and M-CSF origin. Cell Immunol (2013) 281:51-61. doi:10.1016/j.cellimm.2013.01.010

30. Vogt G, Nathan C. In vitro differentiation of human macrophages with enhanced antimycobacterial activity. JClin Invest (2011) 121:3889-901. doi:10.1172/JCI57235

31. Luthra A, Anand A, Hawley KL, Ledoyt M, La Vake CJ, Caimano MJ, et al. A Homology Model reveals novel structural features and an immunodominant surface loop/opsonic target in the Treponema pallidum BamA Ortholog TP_0326. J Bacteriol (2015) 197:1906-20. doi:10.1128/JB.00086-15

32. Dickinson B. Multicolor Flow Cytometry: Principles of Panel Design, Stain Index. Stanford, CA: ISAC (2004).

33. Cervantes JL, Dunham-Ems SM, La Vake CJ, Petzke MM, Sahay B, Sellati TJ, et al. Phagosomal signaling by Borrelia burgdorferi in human monocytes involves toll-like receptor (TLR) 2 and TLR8 cooperativity and TLR8-mediated induction of IFN-beta. Proc Natl Acad Sci U S A (2011) 108:3683-8. doi:10.1073/pnas.1013776108

34. Schmittgen TD, Livak KJ. Analyzing real-time PCR data by the comparative C(T) method. Nat Protoc (2008) 3:1101-8. doi:10.1038/nprot.2008.73

35. McCarthy DJ, Smyth GK. Testing significance relative to a fold-change threshold is a TREAT. Bioinformatics (2009) 25:765-71. doi:10.1093/ bioinformatics/btp053

36. van Voorhis WC, Barrett LK, Nasio JM, Plummer FA, Lukehart SA. Lesions of primary and secondary syphilis contain activated cytolytic T cells. Infect Immun (1996) 64:1048-50.

37. Baughn RE, Musher DM. Secondary syphilitic lesions. Clin Microbiol Rev (2005) 18:205-16. doi:10.1128/CMR.18.1.205-216.2005

38. Radolf JD, Hazlett KR, Lukehart SA. Pathogenesis of syphilis. In: Radolf JD, Lukehart SA, editors. Pathogenic Treponemas: Cellular and Molecular Biology. Northfold, UK: Caister Academic Press (2006). p. 197-236.

39. Radolf JD, Lukehart SA. Immunology of syphilis. In: Radolf JD, Lukehart SA, editors. Pathogenic Treponemes: Cellular and Molecular Biology. Norfolk, UK: Caister Academic Press (2006). p. 285-322.

40. Kunisch E, Fuhrmann R, Roth A, Winter R, Lungershausen W, Kinne RW. Macrophage specificity of three anti-CD68 monoclonal antibodies (KP1, EBM11, and PGM1) widely used for immunohistochemistry and flow cytometry. Ann Rheum Dis (2004) 63:774-84. doi:10.1136/ard.2003.013029

41. Montgomery RR, Lusitani D, De Boisfleury Chevance A, Malawista SE. Human phagocytic cells in the early innate immune response to Borrelia burgdorferi. J Infect Dis (2002) 185:1773-9. doi:10.1086/340826

42. Hawley KL, Olson CM Jr, Iglesias-Pedraz JM, Navasa N, Cervantes JL, Caimano MJ, et al. CD14 cooperates with complement receptor 3 to mediate MyD88-independent phagocytosis of Borrelia burgdorferi. Proc Natl Acad Sci U S A (2012) 109:1228-32. doi:10.1073/pnas.1112078109

43. Fraser CM, Norris SJ, Weinstock GM, White O, Sutton GG, Dodson R, et al. Complete genome sequence of Treponema pallidum, the syphilis spirochete. Science (1998) 281:375-88. doi:10.1126/science.281.5375.375

44. Martinez FO, Gordon S, Locati M, Mantovani A. Transcriptional profiling of the human monocyte-to-macrophage differentiation and polarization: new molecules and patterns of gene expression. J Immunol (2006) 177:7303-11. doi:10.4049/jimmunol.177.10.7303

45. Di Rosa M, Malaguarnera G, De Gregorio C, D’amico F, Mazzarino MC, Malaguarnera L. Modulation of chitotriosidase during macrophage differentiation. Cell Biochem Biophys (2013) 66:239-47. doi:10.1007/s12013-0129471-x

46. Boonnak K, Dambach KM, Donofrio GC, Tassaneetrithep B, Marovich MA. Cell type specificity and host genetic polymorphisms influence antibodydependent enhancement of dengue virus infection. J Virol (2011) 85:1671-83. doi:10.1128/JVI.00220-10

47. Murray PJ, Wynn TA. Protective and pathogenic functions of macrophage subsets. Nat Rev Immunol (2011) 11:723-37. doi:10.1038/nri3073 
48. Basham TY, Merigan TC. Recombinant interferon-gamma increases HLA-DR synthesis and expression. J Immunol (1983) 130:1492-4.

49. Lien E, Sellati TJ, Yoshimura A, Flo TH, Rawadi G, Finberg RW, et al. Toll-like receptor 2 functions as a pattern recognition receptor for diverse bacterial products. J Biol Chem (1999) 274:33419-25. doi:10.1074/jbc.274.47.33419

50. Hawley KL, Martin-Ruiz I, Iglesias-Pedraz JM, Berwin B, Anguita J. CD14 targets complement receptor 3 to lipid rafts during phagocytosis of Borrelia burgdorferi. Int J Biol Sci (2013) 9:803-10. doi:10.7150/ijbs.7136

51. Barratt-Due A, Pischke SE, Nilsson PH, Espevik T, Mollnes TE. Dual inhibition of complement and toll-like receptors as a novel approach to treat inflammatory diseases- $\mathrm{C} 3$ or $\mathrm{C} 5$ emerge together with $\mathrm{CD} 14$ as promising targets. J Leukoc Biol (2016) 101(1):193-204. doi:10.1189/jlb.3VMR0316-132R

52. Kittan NA, Allen RM, Dhaliwal A, Cavassani KA, Schaller M, Gallagher KA, et al. Cytokine induced phenotypic and epigenetic signatures are key to establishing specific macrophage phenotypes. PLoS One (2013) 8:e78045. doi:10.1371/journal.pone.0078045

53. Cervantes JL, La Vake CJ, Weinerman B, Luu S, O'connell C, Verardi PH, et al. Human TLR8 is activated upon recognition of Borrelia burgdorferi RNA in the phagosome of human monocytes. J Leukoc Biol (2013) 94:1231-41. doi:10.1189/jlb.0413206

54. Kang J, Park KH, Kim JJ, Jo EK, Han MK, Kim UH. The role of CD38 in Fcgamma receptor (FcgammaR)-mediated phagocytosis in murine macrophages. J Biol Chem (2012) 287:14502-14. doi:10.1074/jbc.M111.329003

55. Salazar JC, Duhnam-Ems S, La Vake C, Cruz AR, Moore MW, Caimano MJ, et al. Activation of human monocytes by live Borrelia burgdorferi generates TLR2-dependent and -independent responses which include induction of IFN-beta. PLoS Pathog (2009) 5:e1000444. doi:10.1371/journal.ppat.1000444

56. Love AC, Schwartz I, Petzke MM. Borrelia burgdorferi RNA induces type I and III interferons via toll-like receptor 7 and contributes to production of NF-kappaB-dependent cytokines. Infect Immun (2014) 82:2405-16. doi:10.1128/IAI.01617-14

57. Mattiola I, Pesant M, Tentorio PF, Molgora M, Marcenaro E, Lugli E, et al. Priming of human resting NK cells by autologous M1 macrophages via the engagement of IL-1beta, IFN-beta, and IL-15 pathways. J Immunol (2015) 195:2818-28. doi:10.4049/jimmunol.1500325

58. Netea MG, Nold-Petry CA, Nold MF, Joosten LA, Opitz B, Van Der Meer JH, et al. Differential requirement for the activation of the inflammasome for processing and release of IL-1beta in monocytes and macrophages. Blood (2009) 113:2324-35. doi:10.1182/blood-2008-03-146720

59. Guilliams M, Bruhns P, Saeys Y, Hammad H, Lambrecht BN. The function of Fcgamma receptors in dendritic cells and macrophages. Nat Rev Immunol (2014) 14:94-108. doi:10.1038/nri3582

60. Baughn RE, Jorizzo JL, Adams CB, Musher DM. Ig class and IgG subclass responses to Treponema pallidum in patients with syphilis. J Clin Immunol (1988) 8:128-39. doi:10.1007/BF00917901

61. Lukehart SA, Baker-Zander SA, Sell S. Characterization of lymphocyte responsiveness in early experimental syphilis. I. In vitro response to mitogens and Treponema pallidum antigens. J Immunol (1980) 124:454-60.

62. Alderete JF, Baseman JB. Analysis of serum IgG against Treponema pallidum protein antigens in experimentally infected rabbits. Br J Vener Dis (1981) 57:302-8.

63. Baker-Zander SA, Sell S, Lukehart SA. Serum regulation of in vitro lymphocyte responses in early experimental syphilis. Infect Immun (1982) 37:568-78.

64. Sell S, Gamboa D, Baker-Zander SA, Lukehart SA, Miller JN. Host response to Treponema pallidum in intradermally-infected rabbits: evidence for persistence of infection at local and distant sites. J Invest Dermatol (1980) 75:470-5. doi:10.1111/1523-1747.ep12524230

65. Lukehart SA. Activation of macrophages by products of lymphocytes from normal and syphilitic rabbits. Infect Immun (1982) 37:64-9.

66. Xue J, Schmidt SV, Sander J, Draffehn A, Krebs W, Quester I, et al. Transcriptome-based network analysis reveals a spectrum model of human macrophage activation. Immunity (2014) 40:274-88. doi:10.1016/j.immuni. 2014.01.006

67. Martinez FO, Gordon S. The M1 and M2 paradigm of macrophage activation: time for reassessment. F1000Prime Rep (2014) 6:13. doi:10.12703/P6-13

68. Blander JM, Medzhitov R. Regulation of phagosome maturation by signals from toll-like receptors. Science (2004) 304:1014-8. doi:10.1126/science.1096158

69. Balce DR, Rybicka JM, Greene CJ, Ewanchuk BW, Yates RM. Ligation of FcgammaR alters phagosomal processing of protein via augmentation of NADPH oxidase activity. Traffic (2016) 17:786-802. doi:10.1111/tra. 12396

70. Sun D, Ding A. MyD88-mediated stabilization of interferon-gamma-induced cytokine and chemokine mRNA. Nat Immunol (2006) 7:375-81. doi:10.1038/ ni1308

71. Nimmerjahn F, Ravetch JV. Fcgamma receptors as regulators of immune responses. Nat Rev Immunol (2008) 8:34-47. doi:10.1038/nri2206

72. Sellati TJ, Bouis DA, Kitchens RL, Darveau RP, Pugin J, Ulevitch RJ, et al. Treponema pallidum and Borrelia burgdorferi lipoproteins and synthetic lipopeptides activate monocytic cells via a CD14-dependent pathway distinct from that used by lipopolysaccharide. J Immunol (1998) 160:5455-64.

73. Cinco M, Murgia R, Presani G, Perticarari S. Integrin CR3 mediates the binding of nonspecifically opsonized Borrelia burgdorferi to human phagocytes and mammalian cells. Infect Immun (1997) 65:4784-9.

74. Cox DL, Chang P, Mcdowall AW, Radolf JD. The outer membrane, not a coat of host proteins, limits antigenicity of virulent Treponema pallidum. Infect Immun (1992) 60:1076-83.

75. Desrosiers DC, Anand A, Luthra A, Dunham-Ems SM, Ledoyt M, Cummings MA, et al. TP0326, a Treponema pallidum beta-barrel assembly machinery A (BamA) orthologue and rare outer membrane protein. Mol Microbiol (2011) 80:1496-515. doi:10.1111/j.1365-2958.2011.07662.x

76. Anand A, Luthra A, Dunham-Ems S, Caimano MJ, Karanian C, Ledoyt M, et al. $\mathrm{TprC} / \mathrm{D}$ (Tp0117/131), a trimeric, pore-forming rare outer membrane protein of Treponema pallidum, has a bipartite domain structure. J Bacteriol (2012) 194:2321-33. doi:10.1128/JB.00101-12

77. Radolf JD, Norgard MV, Schulz WW. Outer membrane ultrastructure explains the limited antigenicity of virulent Treponema pallidum. Proc Natl Acad Sci U S A (1989) 86:2051-5. doi:10.1073/pnas.86.6.2051

78. Bourell KW, Schulz W, Norgard MV, Radolf JD. Treponema pallidum rare outer membrane proteins: analysis of mobility by freeze-fracture electron microscopy. J Bacteriol (1994) 176:1598-608. doi:10.1128/jb.176.6.1598-1608. 1994

79. Cox DL, Luthra A, Dunham-Ems S, Desrosiers DC, Salazar JC, Caimano MJ, et al. Surface immunolabeling and consensus computational framework to identify candidate rare outer membrane proteins of Treponema pallidum. Infect Immun (2010) 78:5178-94. doi:10.1128/IAI.00834-10

80. van der Poel CE, Spaapen RM, Van De Winkel JG, Leusen JH. Functional characteristics of the high affinity IgG receptor, FcgammaRI. J Immunol (2011) 186:2699-704. doi:10.4049/jimmunol.1003526

81. Zhang Y, Hoppe AD, Swanson JA. Coordination of Fc receptor signaling regulates cellular commitment to phagocytosis. Proc Natl Acad Sci U S A (2010) 107:19332-7. doi:10.1073/pnas.1008248107

82. Alder JD, Friess L, Tengowski M, Schell RF. Phagocytosis of opsonized Treponema pallidum subsp. pallidum proceeds slowly. Infect Immun (1990) 58:1167-73.

83. Marangoni A, Aldini R, Guardigli M, Sambri V, Giacani L, Montagnani M, et al. Phagocytosis of Treponema pallidum and reactive oxygen species production by isolated rat Kupffer cells. Med Microbiol Immunol (2003) 192:183-8. doi:10.1007/s00430-002-0162-x

84. Dufour JH, Dziejman M, Liu MT, Leung JH, Lane TE, Luster AD. IFN-gammainducible protein 10 (IP-10; CXCL10)-deficient mice reveal a role for IP-10 in effector T cell generation and trafficking. J Immunol (2002) 168:3195-204. doi:10.4049/jimmunol.168.7.3195

85. Rupprecht TA, Koedel U, Muhlberger B, Wilske B, Fontana A, Pfister HW. CXCL11 is involved in leucocyte recruitment to the central nervous system in neuroborreliosis. J Neurol (2005) 252:820-3. doi:10.1007/s00415-005-0752-9

86. Hauser MA, Legler DF. Common and biased signaling pathways of the chemokine receptor CCR7 elicited by its ligands CCL19 and CCL21 in leukocytes. J Leukoc Biol (2016) 99:869-82. doi:10.1189/jlb.2MR0815-380R

87. Barry M, Bleackley RC. Cytotoxic T lymphocytes: all roads lead to death. Nat Rev Immunol (2002) 2:401-9. doi:10.1038/nri819

88. Cerwenka A, Lanier LL. Natural killer cell memory in infection, inflammation and cancer. Nat Rev Immunol (2016) 16:112-23. doi:10.1038/nri.2015.9

89. Radolf JD, Deka RK, Anand A, Smajs D, Norgard MV, Yang XF. Treponema pallidum, the syphilis spirochete: making a living as a stealth pathogen. Nat Rev Microbiol (2016) 14:744-59. doi:10.1038/nrmicro.2016.141

90. Lukehart SA. Scientific monogamy: thirty years dancing with the same bug: 2007 Thomas Parran Award Lecture. Sex Transm Dis (2008) 35:2-7. doi:10.1097/OLQ.0b013e318162c4f2 
91. Radolf JD, Kumar S. The Treponema pallidum outer membrane. Curr Top Microbiol Immunol (2017). doi:10.1007/82_2017_44

92. LaFond RE, Molini BJ, Van Voorhis WC, Lukehart SA. Antigenic variation of TprK V regions abrogates specific antibody binding in syphilis. Infect Immun (2006) 74:6244-51. doi:10.1128/IAI.00827-06

93. Houston S, Hof R, Honeyman L, Hassler J, Cameron CE. Activation and proteolytic activity of the Treponema pallidum metalloprotease, pallilysin. PLoS Pathog (2012) 8:e1002822. doi:10.1371/journal.ppat.1002822

94. Lithgow KV, Hof R, Wetherell C, Phillips D, Houston S, Cameron CE. A defined syphilis vaccine candidate inhibits dissemination of Treponema pallidum subspecies pallidum. Nat Commun (2017) 8:14273. doi:10.1038/ ncomms 14273
Conflict of Interest Statement: The authors declare that the research was conducted in the absence of any commercial or financial relationships that could be construed as a potential conflict of interest.

Copyright $\odot 2017$ Hawley, Cruz, Benjamin, La Vake, Cervantes, LeDoyt, Ramirez, Mandich, Fiel-Gan, Caimano, Radolf and Salazar. This is an open-access article distributed under the terms of the Creative Commons Attribution License (CC $B Y$ ). The use, distribution or reproduction in other forums is permitted, provided the original author(s) or licensor are credited and that the original publication in this journal is cited, in accordance with accepted academic practice. No use, distribution or reproduction is permitted which does not comply with these terms. 